\title{
Instrumentation for high-dose, high-resolution dosimetry for microbeam radiation therapy using samarium-doped fluoroaluminate and fluorophosphate glass plates
} DOI:

10.1088/1361-6501/ab404e

10.1088/1361-6501/ab404e

\section{Document Version}

Accepted author manuscript

Link to publication record in Manchester Research Explorer

Citation for published version (APA):

Chicilo, F., Okada, G., Belev, G., Chapman, D., Edgar, A., Curry, R. J., \& Kasap, S. (2019). Instrumentation for high-dose, high-resolution dosimetry for microbeam radiation therapy using samarium-doped fluoroaluminate and fluorophosphate glass plates. Measurement Science and Technology, 31(1), [015201].

https://doi.org/10.1088/1361-6501/ab404e, https://doi.org/10.1088/1361-6501/ab404e

\section{Published in:}

Measurement Science and Technology

\section{Citing this paper}

Please note that where the full-text provided on Manchester Research Explorer is the Author Accepted Manuscript or Proof version this may differ from the final Published version. If citing, it is advised that you check and use the publisher's definitive version.

\section{General rights}

Copyright and moral rights for the publications made accessible in the Research Explorer are retained by the authors and/or other copyright owners and it is a condition of accessing publications that users recognise and abide by the legal requirements associated with these rights.

\section{Takedown policy}

If you believe that this document breaches copyright please refer to the University of Manchester's Takedown Procedures [http://man.ac.uk/04Y6Bo] or contact uml.scholarlycommunications@manchester.ac.uk providing relevant details, so we can investigate your claim.

\section{OPEN ACCESS}


ACCEPTED MANUSCRIPT

\section{Instrumentation for high-dose, high-resolution dosimetry for microbeam radiation therapy using samarium-doped fluoroaluminate and fluorophosphate glass plates}

To cite this article before publication: Farley Chicilo et al 2019 Meas. Sci. Technol. in press https://doi.org/10.1088/1361-6501/ab404e

\section{Manuscript version: Accepted Manuscript}

Accepted Manuscript is "the version of the article accepted for publication including all changes made as a result of the peer review process, and which may also include the addition to the article by IOP Publishing of a header, an article ID, a cover sheet and/or an 'Accepted Manuscript' watermark, but excluding any other editing, typesetting or other changes made by IOP Publishing and/or its licensors"

This Accepted Manuscript is @ 2019 IOP Publishing Ltd.

During the embargo period (the 12 month period from the publication of the Version of Record of this article), the Accepted Manuscript is fully protected by copyright and cannot be reused or reposted elsewhere.

As the Version of Record of this article is going to be / has been published on a subscription basis, this Accepted Manuscript is available for reuse under a CC BY-NC-ND 3.0 licence after the 12 month embargo period.

After the embargo period, everyone is permitted to use copy and redistribute this article for non-commercial purposes only, provided that they adhere to all the terms of the licence https://creativecommons.org/licences/by-nc-nd/3.0

Although reasonable endeavours have been taken to obtain all necessary permissions from third parties to include their copyrighted content within this article, their full citation and copyright line may not be present in this Accepted Manuscript version. Before using any content from this article, please refer to the Version of Record on IOPscience once published for full citation and copyright details, as permissions will likely be required. All third party content is fully copyright protected, unless specifically stated otherwise in the figure caption in the Version of Record.

View the article online for updates and enhancements. 
Instrumentation for High-Dose, High-Resolution Dosimetry for Microbeam Radiation Therapy using Samarium-Doped Fluoroaluminate and Fluorophosphate Glass Plates

F. Chicilo' ${ }^{1)}$, G. Okada $^{2)}$, G. Belev ${ }^{3)}$ D. Chapman ${ }^{4)}$ A. Edgar ${ }^{5)}$ R. J. Curry'), S. $\operatorname{Kasap}^{7)}$

1) Division of Biomedical Engineering, University of Saskatchewan, Canada

2) Kanazawa Institute of Technology, Nonoichi City, Japan

3) Saskatchewan Structural Sciences Centre, University of Saskatchewan, Canada

4) Canadian Light Source, Saskatoon, Canada and the Department of Anatomy and Pharmacology, College of Medicine, University of Saskatchewan, Canada

5) School of Chemical and Physical Sciences, Victoria University of Wellington, New Zealand

6) Photon Science Institute, School of Electrical and Electronic Engineering, University of Manchester, Manchester, UK

7) Department of Electrical and Computer Engineering, University of Saskatchewan, Canada 


\section{Abstract}

We show that $1 \%$ Sm-doped fluoroaluminate (FA) glass plate and a suitably modified fluorescence confocal microscope provide an excellent radiation detection platform for high-dose measurements at high resolution down to the micron scale. We have used a custom-modified fluoroscopic confocal microscope apparatus to scan, separate, detect, and digitize the photoluminescence signals from $\mathrm{Sm}^{3+}$ and $\mathrm{Sm}^{2+}$ ions in both FA and fluorophosphates (FP) glasses within a selected focal depth of the microscope below the sample surface. The response $(R)$ of Smdoped FA and FP glass plates to incident x-ray radiation was studied in detail in which $R$ was defined as the difference in the ratio of photoluminescence (PL) signals from $\mathrm{Sm}^{2+}$ and $\mathrm{Sm}^{3+}$ before and after irradiation. We report on a number of important issues related to the use of these Smdoped FA and FP glass plates in microbeam radiation therapy (MRT) dosimetry: The dependence of the $\mathrm{Sm}^{3+}$ to $\mathrm{Sm}^{2+}$ conversion, and hence $R$ on the dose rate over some four orders of magnitude; the energy dependence of $R$ at a given dose rate for both FA and FP/samples with various concentrations of $\mathrm{Sm}^{3+}$ doping; $R$ vs dose behavior at different energies up to $2000 \mathrm{~Gy}$ air and the derivation of the detector calibration curves; the stability of the Sm-doped plates after they have been exposed; the instrumental limits of the present measurement technique. 


\section{Introduction}

There are currently a number of techniques for the measurement of radiation dose along with a variety of potential materials for use in dosimetry as reviewed, for example, in references $[1,2,3,4,5,6,7]$. Of particular interest is the dosimetery that would be required in the implementation of Microbeam Radiation Therapy (MRT), which is a promising synchrotron-based cancer treatment technique. MRT has been shown to have the potential to improve upon spatially broadbeam radiotherapy methods. The MRT technique is based on the noticeably different responses of tumors and healthy tissue after irradiation by multiple narrow and parallel planar beams of irradiation. In MRT, highly collimated x-rays pass through a multi-slit collimator (MSC), segmenting the incident $\mathrm{x}$-ray radiation before it is delivered to a patient. It has been shown that healthy tissue adjacent to the narrow sections of irradiation helps with the repair of damaged tissues, whereas tumors do not show this ability, allowing for substantial doses to be delivered to a patient with minimal damage to healthy tissue. There have been many papers in the last ten to fifteen years that address various issues related to the use of MRT and its benefits in cancer treatment $[8,9,10,11,12,13,14]$. The technique requires a high incident $\mathrm{x}$-ray energy and must be able to deliver large doses to a patient in a very short timescale in order to maintain the desirable tissue sparing effect associated with the technique.

The accurate measurement of these microbeams is essential for patient care and for treatment planning. The "peak" dose at the center of the microbeam and the "valley" dose between the adjacent microbeams can differ by hundreds of grays over a distance of several microns and incident x-ray energies of interest can vary from $50-250 \mathrm{keV}$. In order to satisfy the dosimetry requirements of MRT, a detector must be able to simultaneously measure both a peak and valley dose with a spatial resolution on the scale of microns, and must be able to do so over a large energy range and at high dose rates. Ultimately, a two-dimensional (2D) cross-sectional image of the dose distribution is required.

Multiple techniques for the measurement of these microbeams have been previously discussed, including Gafchromic films, MOSFET detectors, Si strip detectors, single crystal diamond detectors, polymer gels, fluorescent nuclear track detectors, etc.; see examples in references $[15,16,17,18,19,20]$. The technique must be able to measure doses from a few Grays to thousands of Grays and over various energy ranges. A major problem with many dosimetric materials is the saturation of the sensitivity at high dose or a limited dynamic range that is unable to simultaneously measure both the range from the valley dose (a few Grays) to the peak dose (thousands of grays); a known-problem that has been already discussed in the literature (e.g. [21]). A promising measurement method involves using the valence conversion of rare earth ions which, when embedded in a suitable/material, can serve as a measurement of the delivered dose. Upon irradiation with various forms of excitation, such as x-rays, $\beta$ and $\gamma$-irradiation, and photoexcitation, rare earths have shown the ability to change their valence state in various media $[22,23,24,25,26]$. Of particular interest among the rare earths is samarium, since the emission spectra of $\mathrm{Sm}^{3+}$ and $\mathrm{Sm}^{2+}$ ions are easily distinguishable and emit in the orange and red regions of the spectrum respectively, which are well suited for detection by photomultiplier tubes (PMTs).

The conversion process for $\mathrm{Sm}^{3+}$ to $\mathrm{Sm}^{2+}$ is strongly dependent on the host material. Previous work has shown that Sm-doped FP and FA glasses can be used as dosimetric detectors, 
which have the capability of measuring both large doses and the peak-to-valley dose ratio (PVDR) at high resolution, both are important considerations in the future success of MRT. These Smdoped glass plate dosimeters utilize the distinguishable photoluminescence (PL) signals from the conversion of $\mathrm{Sm}^{3+}$ to $\mathrm{Sm}^{2+}$ as a function of the dose delivered. These PL signals are then measured using a modified fluorescence confocal microscopy detection system that is tuned to the emission wavelengths of these ions. Using this method it has been shown that resolution on the order of microns can be achieved [27,28,29,30,31,32,33,34,35]. This works investigates one of the most important issues in the calibration of any detector for accurate dose measurement: the dependence of the response of the detector to the incident $x$-ray energy and the incident dose rate. We have examined the conversion of $\mathrm{Sm}^{3+}$ to $\mathrm{Sm}^{2+}$ of Sm-doped FA and FP glasses over a wide range of dose rates (four orders of magnitude) and energy values (35 to $130 \mathrm{keV}$ ) and how these Sm-doped plates can be calibrated so that they measure the correct incident dose.

In the present paper, we discuss the conversion of $\mathrm{Sm}^{3+}$ to $\mathrm{Sm}^{2+}$ in these materials and how the conversion process is affected by the dose rate and incident x-ray energy. An important factor in the success of MRT is the high incident dose rate which helps minimize any "smearing" of the microbeams that may occur from the patient's movement, or from micron level shifts resulting from vascular flow within the irradiated tissue. An additional important consideration is that of the incident x-ray energy; the energy must be high enough to penetrate deeply into patient tissue and ensure that sufficient dose is delivered to the desired region. Ideally, the response of a dosimeter should be independent of the incident x-ray energy as well as the incident dose rate. In practice, however, a dosimeter response needs to be calibrated when the energy range of the incident X-rays is large [36].

The measurement of the PL from $\mathrm{Sm}^{3+}$ and $\mathrm{Sm}^{2+}$ ions was implemented by using a fluorescence confocal microscope as mentioned above. We have also examined the dependence of the response $\left(\mathrm{Sm}^{3+}\right.$ to $\mathrm{Sm}^{2+}$ conversion) of the $\mathrm{Sm}$-doped glasses on the focal depth below the sample surface in the confocal microscope measurements as a function of x-ray energy. If the response of the dosimetric plate depends on the focal depth into the sample, this dependence needs to be included in the calibration characteristics.

The dependence of the $\mathrm{Sm}^{3+}$ to $\mathrm{Sm}^{2+}$ conversion on the amount of Sm doping in FA and FP glasses has been examined preyiously $[29,34]$. In this work we extend the previous study by examining the stability of the Sm-doped glasses shortly after they have been irradiated up to a period of 15 days. Most importantly, we examine the energy dependence of the $\mathrm{Sm}^{3+}$ to $\mathrm{Sm}^{2+}$ conversion for different amounts of Sm-doping at a given dose. The Sm-doped FA glass plates in this work are able to measure doses up to $2 \times 10^{3} \mathrm{~Gy}$ in air and the measurement is independent of the dose rate; an important factor in the use of this technique in MRT.

\section{2. $\mathrm{Sm}^{3+}$-Doped Fluoroaluminate and Fluorophosphate Glass Plates}

Sm doped glasses were synthesized using a melt quenching technique previously described in detail elsewhere [27,28,29,30,31,32,33,34,35]. Starting materials were mixed in a glove box in a dry nitrogen atmosphere and loaded in a carbon crucible where the mixture was then melted in an $\mathrm{RF}$ furnace at $1000^{\circ} \mathrm{C}$ for 120 minutes. The glass was then quenched on a temperature controlled plate at $380^{\circ} \mathrm{C}$ for 8 hours in an argon atmosphere in order to relieve internal stress and prevent cracking. The composition for FA glass in molar percentage is $10.0 \mathrm{MgF}_{2}-35.0 \mathrm{AlF}_{3}-20.0 \mathrm{CaF}_{2}$ 
$-10.0 \mathrm{SrF}_{2}-(15-x) \mathrm{YF}_{3}-10.0 \mathrm{BaF}_{2}-x \mathrm{SmF}_{3}$ and for FP glass is $10.0 \mathrm{MgF}_{2}-(34.4-x) \mathrm{AlF}_{3}-$ $30.4 \mathrm{CaF}_{2}-15.2 \mathrm{SrF}_{2}-10.0 \mathrm{Sr}\left(\mathrm{PO}_{3}\right)_{2}-x \mathrm{SmF}_{3}$ where $x$ is the concentration of $\mathrm{SmF}_{3}$, which can be varied from $0.1 \%$ to $10 \%$. Following synthesis, the glass materials were polished and cut into approximately $2 \mathrm{~mm}$ by $3 \mathrm{~mm}$ rectangular pieces for subsequent experiments. A typical glass plate thickness was $\sim 1.5 \mathrm{~mm}$. All percentages quoted hereafter are in mol.\%. Some 120 samples were prepared for all the measurements. The density of the samples were measured by using the Archimedes principle of change in the measured weight of the sample in a liquid of known density. The sample density was $3.74 \mathrm{~g} \mathrm{~cm}^{-3}$. The refractive index of the samples was approximately 1.5 over the PL wavelengths used in this work [37,38].

One of the FA glass samples (where $x=0$ in the composition formula) was ion-implanted near the surface of the sample as described previously [35]. The ion-implantation generated a distribution of $\mathrm{Sm}^{2+}$ ions within a depth $1 \mu \mathrm{m}$ and a peak concentration located at a $0.60 \mu \mathrm{m}$ depth from the surface. The luminescence properties of these glasses have been already described [35]. The purpose of this $\mathrm{Sm}^{2+}$ ion-implanted sample is to provide a verification for the axial luminescence collection range in the confocal photoluminescence confocal microscope.

\section{Single Energy and Polychromatic X-Ray Irradiation, Dose and Dose Rate Delivery}

Polished and cut samples were taken to the Biomedical Imaging and Therapy (BMIT) 05ID-2 beamline at the Canadian Light Source (CLS, the Canadian synchrotron), for x-ray irradiations. Using the facilities at the BMIT beamline the incident $\mathrm{x}$-ray energy is tuned using a bent Laue double-crystal monochromator, which allows for monochromatic incident high energy $\mathrm{x}$-rays to be selected with a resolution $(\Delta E / E)$ of $10^{-3}$. When performing the irradiations for dose rate and energy dependence experiments, the total dose delivered to each sample was kept constant at 200

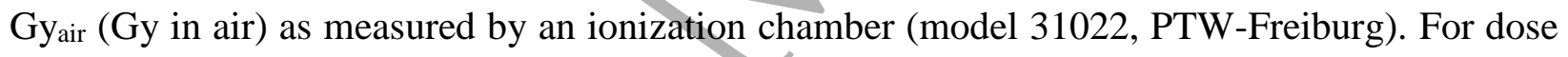
rate measurements, the incident x-ray energy was kept constant at $50 \mathrm{keV}$, which is closest to the peak photon flux rate for the BMIT beamline and allows the maximum dose rate range to be delivered to a sample. It is important to emphasize that all dose rate measurements were done at one given energy and the total dose was kept constant. Likewise, for the samples irradiated while investigating the energy dependence experiments, the incident dose rate was kept constant at 175 $\mathrm{mGy} / \mathrm{s}$, which is the quoted dose value in air at the surface of the sample i.e. entrance dose in air. The incident $\mathrm{x}$-ray energy was selected using a monochromator where the x-ray energy range was between $35 \mathrm{keV}$ and $130 \mathrm{keV}$. The energy range is similar to that recently used in an MRT optimization study [39]. In order to modify the delivered dose rate to each sample, the wiggler magnetic field was modified between 2 and 3.9 $\mathrm{T}$ and additional aluminum filters were placed in the beam path to reduce the dose rate without modifying the x-ray energy. In the case of all samples, a $1 \mathrm{~mm}$ aluminum filter was present in the beam. Irradiation of collimated microbeams on Sm-doped glass plates were performed using a tungsten multislit collimator (MSC) with a slit width of $50 \mu \mathrm{m}$ where the slits are separated by $400 \mu \mathrm{m}$ (center-to-center distance). The collimator was manufactured by Usinage et Nouvelles Technologies, Morbier, France. Samples were irradiated in the dark and wrapped in aluminum foil until readout experiments were performed using a modified fluorescence confocal microscope described below.

X-ray irradiation experiments involving PL spectra and signal stability were completed using a FAXITRON x-ray cabinet with a tungsten anode operating at $110 \mathrm{kVp}$ at an approximate 
dose rate of $40 \mathrm{~Gy} / \mathrm{min}$ in air. This dose value represents the dose delivered in air at the surface of the sample, and not within the sample itself. The FAXITRON x-ray source is polychromatic with a mean energy of $49.3 \mathrm{keV}$ taken from fluence simulations given at the Siemens website [40]. The exposure rate was measured by an ionization chamber (Keithley 35050). PL spectra of irradiated samples were measured using an ASEQ fiber input mini-spectrometer with spectral resolution better than $1 \mathrm{~nm}$. The excitation source used was a $405 \mathrm{~nm}$ laser diode.

\section{Optical Measurement Technique: Modified Fluorescence Confocal Microscope}

Response values for samples irradiated were measured using a custom confocal fluorescence microscopy readout system, which has been described in some detail previously [28,29,32,33,34]. Figure 1 shows a schematic of the confocal microscopy apparatus. The apparatus was a modified commercial confocal microscope (MultiProbe 2001 TM CLSM, Molecular Dynamics). The excitation beam at $473 \mathrm{~nm}$ (blue) was generated by a diode-pumped solid-state (DPSS) laser, whose beam is reflected by a $570 \mathrm{~nm}$ dichroic mirror (DM) towards an objective lens that focuses the laser at a selected focal depth within the sample. The intensity of the blue excitation laser beam in readout during confocal scanning was $0.5 \mu \mathrm{W}$. Upon excitation, $\mathrm{Sm}^{3+}$ and $\mathrm{Sm}^{2+}$ ions emit distinct and separable PL signals which are collected from the objective lens and guided towards a set of photomultiplier tubes (PMT). These signals are focused using an achromatic lens onto a pinhole and the resulting beam is then directed towards a $650 \mathrm{~nm}$ dichroic mirror which separates the $\mathrm{Sm}^{3+}$ and $\mathrm{Sm}^{2+}$ signals towards two separate PMTs fronted with a $600 \mathrm{~nm}$ band-pass filter (BPF) and a $660 \mathrm{~nm}$ long-pass filter (LPF), respectively. Figure 2 shows the spectral characteristics of the excitation and the two photomultiplier tubes with filters. The $\mathrm{Sm}^{3+}$ and $\mathrm{Sm}^{2+}$ signals are measured simultaneously and PL signals are digitized for calculation of the response of the Smdoped glass plate.

The use of the confocal readout system requires the objective lens to be suitably placed below the sample so that the focal point in the sample that determines the volume of collection is well defined. This process is achieved by using a filter to block the $473 \mathrm{~nm}$ emission from the DPSS laser and allow the pump laser diode emission $(\lambda=808 \mathrm{~nm})$ from the blue laser to pass through a filter. The reflection of this $808 \mathrm{~nm}$ beam from the sample surface is then recorded by changing the objective lens height from the sample surface, until a maximum reflection from the surface is registered. Once the location of the sample surface is known, the actual depth of the focal point inside the sample from the surface can be easily determined through straightforward optics. A movement of the objective by a distance $D$ corresponds to the movement of the focal point in the sample by $d$ where $d=D / n$, where $n$ is the refractive index of the sample, as shown in Figure 3 (a). The motion $D$ is measured and converted to $d$ in plots where the PL measurements were recorded as a function of distance from the sample.

It is important to identify the laser excitation volume and the volume from which the PL signals are collected in the confocal microscope set-up in Figure 1. As shown in Figure 3 (b), the $470 \mathrm{~nm}$ excitation volume includes the cone-volume above the focal point up to the sample surface and the cone-volume below the focal point. The volume responsible for the PL signals however is different in the vertical $(z)$ and lateral $(x, y)$ directions. The vertical range $\Delta z$ of signal collection, the vertical resolution, for an infinitely small pinhole would also be diffraction limited. In the present case, to obtain the best signal-to-noise ratio over a very large dynamic range (from 5 - 
$2000 \mathrm{~Gy})$, the highest pinhole size was selected $(200 \mu \mathrm{m})$ so the vertical range $\Delta z$ was much larger than the diffraction limited value and is determined experimentally as described below.

Figure 4 shows the PMT1 signal obtained from the $\mathrm{Sm}^{2+}$-ion implanted FA glass as a function of distance $d$ below the surface. The signal peak is roughly at $1 \mu \mathrm{m}$ and the PMT1 signal decays and is half at about $d \approx 21 \mu \mathrm{m}$. The full width at half maximum (FWHM) vertical range $\Delta z$ for PL signal collection is therefore about $42 \mu \mathrm{m}$. This vertical range $\Delta z$ represents approximately the vertical resolution of the confocal microscope used and, in the current application, it is significantly larger than typical confocal applications where $\Delta z$ would be a few microns; the present measurement uses a large pinhole to capture PL signals with acceptable $\mathrm{S} / \mathrm{N}$ ratio at the low dose range. The significance of the results in Figure 4 is that if we place the focal point at $d$ $=20 \mu \mathrm{m}$, then the vertical region from the surface to a depth of about $40 \mu \mathrm{m}$ will primarily contribute to the PL signal, that is, we can exclude the spurious PL signals from the regions below and laterally further than $\Delta x$ (the width of the focal point). Figure 5 shows the $\mathrm{Sm}^{3+}$ signal from PMT2 as a function of $d$. As expected this signal increases with $d$ as the PL capture range is moved more into the sample. As will be shown below in the results section, the response of the Sm-doped plate to $\mathrm{x}$-ray exposure remains constant up to about $d \approx 20 \mu \mathrm{m}$, which is the $d$ chosen in this work. There is one more distinct advantage to using a confocal microscope to probe only the depth $\Delta z$ from the surface, which is roughly $40 \mu \mathrm{m}$. Over this distance, the radiation induced photodarkening is negligible, where this had to be considered in examining the PL from the whole sample with a thickness of a few millimeters as shown in reference [32], and included in the dosimetric response.

\section{Lateral Resolution in Optical Measurements and the Spatial Microbeam Profile}

In the lateral direction, the resolution defined as $\Delta x$ in Figure 3 (b), is determined by diffraction effects and depends on the lens objective characteristics (numerical aperture, NA) and the wavelength of interest, $\lambda$, through the relationship $\Delta x \approx 0.61 \lambda / \mathrm{NA}$ [41]. For $\lambda \approx 700 \mathrm{~nm}$ and NA $=$ 0.75 for the objective lens used, $\Delta x \approx 0.5 \mu \mathrm{m}$. Figure 6 demonstrates the high image resolving power of the current system by displaying the XY scanned PL from a $4 \mu \mathrm{m}$ fluorescent microsphere, obtained from MultiSpeck ${ }^{\mathrm{TM}}$ Multispectral Fluorescence Microscopy Standard, Molecular Probes.

The measurements in Figure 6 were independently verified by imaging the same slide on a commercial two-photon microscope (Prairie Technology Ultima IV). The lateral resolution of the microscope was calibrated with a stage micrometer $2 \mathrm{~mm} / 0.01 \mathrm{~mm}$ with overall accuracy $0.0015 \mathrm{~mm}$ (S20, Pyser Optics).

The resolution capability of the microscope was also examined by scanning a 1951 USAF resolution plate collected through the reflection of the incident laser on the target surface through the $20 \times$ objective lens. The image from the latter scan is shown in Figure 7, and shows group 6 and 7 of the resolution plate where the smallest line widths are $4.38 \mu \mathrm{m}$ and $2.19 \mu \mathrm{m}$, respectively. They can be easily resolved.

The scanning speed of the confocal microscope system is largely dependent on the desired resolution and field of view. The system uses a galvo mirror to achieve a rectangular raster scanning method, where the image is scanned left to right in the $x$-direction and then is moved 
down to the next line in the $y$-direction where the process is repeated. Using the $20 \times$ objective lens gives an approximate field of view (FOV) of $0.75 \times 0.75 \mathrm{~mm}$. A typical scan setting using the $20 \times$ objective lens collects an image with approximately $500 \times 500$ pixels, although higher resolutions can be achieved $(2500 \times 2500$ pixels $)$. The reason for selecting a lower resolution is due to the relatively long PL decay lifetimes of the $\mathrm{Sm}^{3+}$ and $\mathrm{Sm}^{2+}$ ions, due to so called "forbidden" $4 \mathrm{f} \rightarrow 4 \mathrm{f}$ transitions that are characteristic of samarium ions, which are between 4 and $10 \mathrm{~ms}$ [35]. Signal collection requires a dwell time at each pixel that is larger than the PL lifetime decays of the Sm ions, and so each pixel is excited for $20 \mathrm{~ms}$ before moving to the adjacent pixel. The Time it takes to scan a field of view along $x$ is 500 pixels $\times 0.02 \mathrm{~s}$ or $5.3 \mathrm{~s}$. The scan of the whole field of view $(500 \times 500$ pixels $)$ is then $5000 \mathrm{~s}$ or about $1.4 \mathrm{~h}$. At the highest achievable resolution $((2500 \times$ 2500 pixels) this time approximately is $34.7 \mathrm{~h}$. This measurement time could be reduced significantly by scanning only the region of interest within the FOV or creating a more efficient scanning method. Further, samarium doped oxyfluoride glass ceramics have been shown to be capable of high resolution microbeam dosimetry, and exhibit parity-allowed $5 \mathrm{~d} \rightarrow 4 \mathrm{f}$ transitions which have PL decay lifetimes on the order of nanoseconds [28], cutting the read-out time from hours to minutes.

A spatial profile of a microbeam as recorded on $\mathrm{a} \mathrm{Sm}^{3+}$-doped FA glass plate under $\mathrm{x}$-ray irradiation at the Canadian Light Source is shown in Figure 8. The image on the left is a 2D image of a single irradiated microbeam on a $1 \%$ Sm-doped FA glass slide where the incident beam was put through a MSC. The incident x-ray energy was selected to be $50 \mathrm{keV}$ and the total dose delivered was measured as $200 \mathrm{~Gy}_{\text {air }}$ before passing through the collimator. The collimator has a series of $50 \mu \mathrm{m}$ slits which are separated by a distance of $400 \mu \mathrm{m}$, center to center. The circles in the plot on the right of Figure 8 are the experimental points from the confocal lateral scan whereas the solid curve is a Monte Carlo simulation of the beam through the collimator $[42,43,44]$. The measured profile agrees very well with simulations and highlights the high resolution that can be obtained with these Sm-doped glasses in a fluorescence confocal microscope readout. This work only considered the systematic calibration of the system for dose measurement and does not report XY scans of PL images for studying the beam shape at different energies; this will be reported in the future.

\section{X-Ray Response Calibration Curves and Equations}

The change of valence from $\mathrm{Sm}^{3+}$ to $\mathrm{Sm}^{2+}$ upon $\mathrm{x}$-ray irradiation can be used as measure of the $\mathrm{x}$ ray dose delivered. Previous work with Sm-doped FA and FP glasses examined the conversion of $\mathrm{Sm}^{3+}$ to $\mathrm{Sm}^{2+}$ over a wide range of doses and demonstrated the reusability of bulk doped samples by reversing the valence change from $\mathrm{Sm}^{2+}$ to $\mathrm{Sm}^{3+}$ after extended UV exposure or annealing above the glass transition/temperature [27,28,29,30,31,32,33,34,35]. The glass transition temperatures for FA and FP glasses were measured to be $440{ }^{\circ} \mathrm{C}$ and $462{ }^{\circ} \mathrm{C}$, respectively. The $\mathrm{Sm}^{3+}$ ions act as electron trapping centers in order to become $\mathrm{Sm}^{2+}$. It appears as though the conversion process is controlled by hole trapping, since, once the glass samples have reached saturation (no further conversion to $\mathrm{Sm}^{2+}$ ), the presence of $\mathrm{Sm}^{3+}$ ions can still be observed. Additionally, increasing the overall doping concentration of $\mathrm{Sm}^{3+}$ ions does not lead to a greater number of valence conversions to $\mathrm{Sm}^{2+}$. Figure 9 shows the distinct and separable PL spectra and primary atomic excitation levels of $\mathrm{Sm}^{3+}$ and $\mathrm{Sm}^{2+}$ in $1 \% \mathrm{Sm}$ doped FA glass before and after 
irradiation. The response $R$, as opposed to responsivity (which is response per unit input into the sensor) of a Sm-doped glass plate detector is defined as,

$$
\text { Response } \equiv \frac{\mathrm{I}_{\mathrm{PMT}(2+)}}{\mathrm{I}_{\mathrm{PMT}(3+)}} \text { Irradiated }-\frac{\mathrm{I}_{\mathrm{PMT}(2+)}}{\mathrm{I}_{\mathrm{PMT}(3+)}} \text { Non-irradiated }
$$

where $\mathrm{I}_{\mathrm{PMT}(2+)}$ and $\mathrm{I}_{\mathrm{PMT}(3+)}$ are the measured signal intensities from the two photomultiplier tubes which measure the emissions from $\mathrm{Sm}^{2+}$ and $\mathrm{Sm}^{3+}$ through a $660 \mathrm{~nm}$ long-pass filter (IPMT(2+)) and a $660 \mathrm{~nm}$ band-pass filter (IPMT(3+)), respectively as shown in Figure 2. It is possible to formulate a more rigorous definition for the conversion and hence the response by examining the whole PL spectra before and after irradiation and deriving the weighting coefficients needed to combine the individual $\mathrm{PL}\left(\mathrm{Sm}^{3+}\right)$ and $\mathrm{PL}\left(\mathrm{Sm}^{2+}\right)$ to generate the overall spectrum from the irradiated sample as demonstrated in [32]. This approach was not used here due to the computational times involved in finding the weighting factors as well as the distinct advantage of implementing the definition above in the hardware i.e. by using two separate PMTs with filters to capture the $\mathrm{Sm}^{3+}$ and $\mathrm{Sm}^{2+}$ emission bands. During readout there is some unavoidable bleaching of the $\mathrm{Sm}^{2+}$ as the result of the excitation source, thus the calculated response of the sample is taken as the average response within the 0.5 second period following the opening of the shutter.

Previous works have shown that varying the concentration of Sm dopants within the bulk sample leads to differing conversion rates of the $\mathrm{Sm}$ ions, most notably, the lower the concentration, the larger the number of ions converted from $\mathrm{Sm}^{3+}$ to $\mathrm{Sm}^{2+}$ and thus greater the response of the material $[28,34]$. It has also been shown that the host glass material plays a role in the dynamic range of the dosimeter; prior work has shown that both FA and FP glasses have exhibited a dynamic range of 1 Gyair to $10 \mathrm{kGy}_{\text {air }}$ [34]. For the purposes of this research, we have investigated multiple Sm dopant concentrations embedded in two hosts, FA and FP, to study the effect of the dose rate and energy of x-rays on the conversion from $\mathrm{Sm}^{3+}$ to $\mathrm{Sm}^{2+}$. It is also instructive to note that while FA and FP glass materials have been shown to be excellent host materials for the valance conversion of Sm-ions, photodarkening is present within the glasses after large doses have been deposited. This is particularly strong in FP glasses, which causes the transmittance to drop in the same region of wavelengths as the emission of $\mathrm{Sm}^{3+}$ [32]. There is a very small change in the transmission at $600 \mathrm{~nm}$ with $\mathrm{x}$-ray irradiation in FA glasses, so the photodarkening of FA glasses was ignored. Error bars are determined by measuring the standard deviation of the response across a two dimensional uniformly irradiated glass plate. A total of 120,531 data points (response values) were measured and the standard deviation was found to be $4.57 \%$. The latter represent the error in the response value.

The response values after irradiating $1 \% \mathrm{Sm}$ doped FA and FP glasses over a dose rate range that covers roughly four orders of magnitude were measured. Figure 10 shows that there is no evidence of a dose rate dependence from the lowest $(0.7 \mathrm{mGy}$ air $/ \mathrm{s})$ to the highest $(5 \mathrm{~Gy}$ air $/ \mathrm{s})$ dose rates available at the BMIT beamline at the CLS using monochromatic energy x-rays. It is possible to achieve higher dose rates by using a polychromatic beam, but the goal of this experiment was to show whether there is any dependence at all on the dose rate at a given energy. In all samples, the incident $\mathrm{x}$-ray energy was selected to be $50 \mathrm{keV}$ and the overall dose delivered was chosen as 200 Gyair as measured by a high dose ionization chamber. The choice of $50 \mathrm{keV} x$-ray energy was based on peak photon flux rates at the CLS and, of course, the need to relate the present work to 
previous experiments at the CLS where $50 \mathrm{keV}$ was used. The results from Figure 10 clearly show that the response $R$ is independent of the dose rate in both of the host glass materials. This is a distinct advantage since the dose calibration curve for relating the response to the actual dose does not need to be modified for different dose rates, i.e. the calibration curve can be used under all dose rates.

The $\mathrm{x}$-ray energy dependence of the response was measured for both Sm-doped glasses, FA and FP, as shown in Figure 11 from 35 to $130 \mathrm{keV}$. For all irradiated glasses in Figure 11 the dose rate was kept constant at $0.175 \mathrm{~Gy}_{\text {air }} / \mathrm{s}$ and the total dose delivered was maintained at 200 Gyair. Notice that there is a strong dependence on the x-ray energy as the Sm-dopant concentration is decreased from $5 \%$ to $0.2 \%$ in FA glass. $5 \%$ Sm doped FA glass shows not only a much smaller response but also a much weaker energy dependence, while the $1 \%$ Sm doped FA glass exhibits a large response and a stronger $\mathrm{x}$-ray energy dependence than that for $5 \% \mathrm{Sm}$. $1 \% \mathrm{Sm}$ doped FP glass has a smaller response and a weak energy dependence.

Figure 12 compares the dose response curve for 1\% Sm-doped FA glass with energies ranging from $40-120 \mathrm{keV}$. Each point on the graph corresponds to an individual piece of sample, meaning that the total dose is not an accumulative dose. Put differently, using a new sample for each dose (exposure) avoids using a single sample in multiple irradiations. These results indicate that, for a wide range of energies, the dose delivered can be measured from a range of 5 Gy to $2000 \mathrm{~Gy}$, which covers the dose range for most MRT applications. The response $(R)$ vs Dose $(D)$ measurements have been plotted on a log-log scale in Figure 12. Although the initial rise is linear, as the dose becomes larger, the linearity is lost. The simplest assumption would be a first order kinetic equation for the rate of conversion under a limited supply, which implies an exponential rise towards saturation i.e.

$$
R=R_{o}\left[1-\exp \left(-D / D_{o}\right)\right]
$$

where $R_{o}$ and $D_{o}$ are the constants. The best fit parameters of Equation to the data in Figure 12 are shown in Table 1. It can be seen that Equation (1) provides a good fit to the data over the whole dose range and energy range. Under low doses, $R=\left(R_{o} / D_{o}\right) D$ i.e. $R$ is linearly proportional to the incident dose. The ratio $R_{o} / D_{o}$ represent the slope of the initial linear rise in $R$ vs $D$ and hence the initial sensitivity of the detector glass. The inset in Figure 12 shows $R_{o} / D_{o}$ vs. X-ray energy $E$ and it can be seen that $R_{o} / D_{o}$ decreases with the photon energy, which accounts for the lower dosesensitivity at higher energies. As a point of interest, a parabolic fit was also tried in which $R=a D$ $-b D^{2}$, where the second term causes the fall of $R$ below the linear behavior as $D$ increases. While the parabolic equation also has two constants as Equation (1), the fit to the parabolic equation was found to be worse. A power law fit of the form $R=A D^{m}$ (where $A$ and $m$ are constant) yields $R^{2}$ coefficients that are worse than both the exponential and the parabolic forms. The curves in Figure 12 serve as the calibration curves for the $1 \% \mathrm{Sm}^{3+}$-doped FA glasses at different $\mathrm{x}$-ray energies. We can also speculate on the saturation behavior by noting that the dose needed to reach $90 \%$ saturation $D_{90}=2.3 D_{o}$ which, from Table 1 , is $2,335 \mathrm{~Gy}$ at $120 \mathrm{keV}$.

For all the previous figures in this work, the total focal depth from the sample surface $(d)$ has been set to $20 \mu \mathrm{m}$ as discussed in Section 2. However, by changing the incident energy, this can also play an important factor in the response of the Sm-doped glass material as a function of 
both the incident $\mathrm{x}$-ray energy and the selected confocal depth. Prior published work involving Sm-doped FA glasses irradiated at the CLS had used an energy of $50 \mathrm{keV}$ and a focal depth of 20 $\mu \mathrm{m}$ to measure the response values [28,34]. Figure 13 compares the focal depth against the response values for two $\mathrm{x}$-ray energies, $40 \mathrm{keV}$ and $120 \mathrm{keV}$, and shows that response can be shown to be constant as the focal depth increases up to a certain depth, depending on the incident $\mathrm{x}$-ray energy, then the response decreases. Increasing the focal depth beyond $40 \mu \mathrm{m}$ and attenuation of the emitted light within the host glass begins to affect the collection of light as well as the decrease in the $\mathrm{Sm}^{2+}$ concentration. These results indicate that over such a large energy range as is investigated in this paper, the energy dependence can influence the response values and requires careful attention during calibration.

As part of the work in this paper, multiple concentrations of Sm-dopants have been investigated towards characterizing the energy and dose rate dependence of FA and FP glass samples. Figure 10 and Figure 11 show that the host glass material (FA vs FP) and smaller concentrations of Sm-dopants in the host glass $(0.2$ to $5 \% \mathrm{Sm})$ give rise to a larger conversion of $\mathrm{Sm}^{3+}$ to $\mathrm{Sm}^{2+}$ under the same irradiation conditions. An important consideration in these materials is the overall stability of the sample, that is, the response of the sample should not change between the time of irradiation and readout. Figure 14 shows the change in the response $R$ of various Smdoped glass plates as a function of time right after irradiation up to 15 days. As can be seen from Figure 14, the Sm-dopant concentration plays an important role in the stability of the samples. The spontaneous reconversion from $\mathrm{Sm}^{2+}$ to $\mathrm{Sm}^{3+}$ appears to be related to the availability of hole traps, since $1 \% \mathrm{Sm}$-doped FA glass appears to be very stable after irradiation, whereas the response of $0.2 \% \mathrm{Sm}$-doped FA glass appears to decrease noticeably immediately after irradiation. Regardless of concentration, it appears that the response values of all samples appear to be stable after 24 hours following the cessation of irradiation. The above result indicate that $1 \% \mathrm{Sm}$-doping is the most suitable concentration for dosimetric purposes due to the stability of the irradiated signal and the capability of detecting response values over a wide range of incident $\mathrm{x}$-ray energies. While $0.2 \% \mathrm{Sm}$ is more sensitive (Figure 11), its stability is worse than $1 \% \mathrm{Sm}$ (Figure 14).

\section{Discussion and Critique}

Previous work with Sm-doped FA and FP glasses examined the conversion of $\mathrm{Sm}^{3+}$ to $\mathrm{Sm}^{2+}$ over large dose ranges and how these samples could be shown to be reusable through the process of UV exposure or thermal annealing around the glass transition temperature by reconverting the $\mathrm{Sm}^{2+}$ ions back to their original $\mathrm{Sm}^{3+}$ state, demonstrating their usefulness as a dosimetric detector for MRT. Overall it has been shown that after long periods of irradiation, photodarkening is present in both FA and FP glass samples, although the changes in absorbance for FA glasses are primarily in the UV region, whereas FP glasses can become so dark that they may become of little use for high-dose dosimetry. These results confirm the findings of this research, which show that when 1\% Sm-dopant FA and FP samples are exposed to identical irradiation conditions, the response values are higher for FA glasses than FP as shown in Figure 10, Figure 11 and Figure 14. Overall, the properties of FP glasses are better understood than those of FA glasses, which makes them useful for research purposes. FP glasses have evidence of phosphorous-oxygen hole and electron centers (POHC and POEC) which have been well studied [27], while the hole traps within FA glasses are tentatively associated with fluorine complexes and oxygen contamination $[45,46,47,48]$. The conversion of $\mathrm{Sm}^{3+}$ to $\mathrm{Sm}^{2+}$ is controlled by a hole trapping process, which is 
clearly evident when we compare the overall response values of FA glass samples in which the Sm-dopant concentration has been varied, as in Figure 10 and Figure 14. These indicate that the increase in the number of total electron acceptors, $\mathrm{Sm}^{3+}$ ions, does not lead to a higher conversion, i.e. response. This result is somewhat non-intuitive, but is apparent when comparing the response values of $0.2 \%$ and $5 \% \mathrm{Sm}$ doped FA glasses in Figure 10 and Figure 14, which have a marked difference in response values to the same irradiation conditions. While lower concentrations lead to larger a conversion from $\mathrm{Sm}^{3+}$ to $\mathrm{Sm}^{2+}$, there is a trade off in the stability of the sample. Figure 14 indicates that $1 \%$ Sm-doped FA is a stable sample that does not change after irradiation while still showing strong conversion, and is an ideal candidate for MRT dosimetry purposes.

The dose rate and energy dependence of dosimeters is an important consideration. MRT relies on adjacent healthy tissue aiding in the repair of tissue damaged from radiation. The success of MRT requires minimal movement of the patient in order to prevent "smearing" of the microbeams which would cause a decrease in the PVDR. MRT uses dose rates up to thousands of $\mathrm{Gy} / \mathrm{s}$, so the response of the detector should not change as the incident dose rate is altered. Figure 10 indicates that there is no evidence of a dose rate dependence resulting from the irradiation of the samples, which is an important discovery in this work. It appears that the conversion from $\mathrm{Sm}^{3+}$ to $\mathrm{Sm}^{2+}$ and the hole trapping process is not influenced by the flux of incident $\mathrm{x}$-rays.

The dependence of the response on the incident dose is shown in Figure 12 at different photon energies. It is important to emphasize that each point represents a different sample so that the dose is not accumulated dose. Using a single sample and then carrying out measurements from one dose to the next would not necessarily represent the true response vs. dose characteristics because in the latter case the dose would be a "cumulative dose". The dependence of the response on the x-ray energy can be understood from the dependence of the actual energy deposited as the photon energy increases. Although the incident dose in air is the same for all the exposures ( $1 \mathrm{kGy}$ in air) in Figure 11, the deposited energy in the FA glass decreases with photon energy because the photoelectric effect's cross section falls more rapidly with energy than the linear attenuation coefficient; around $40 \mathrm{keV}$, they are approximately the same. Consider the change in the response in Figure 11 from $40 \mathrm{keV}$ to $130 \mathrm{keV}$. The photon fluence $\Phi_{\text {ph }}$ in the two cases are different. We can calculate $\Phi_{\mathrm{ph}}$ from the Boone equation [49],

$$
\Phi_{\mathrm{ph}}=\frac{1}{a+b \sqrt{E} \ln E+\frac{c}{E^{2}}} \quad \text { [photons } \mathrm{mm}^{-2} \mathrm{mR}^{-1} \text { ] }
$$

here $E$ is the photon energy in $\mathrm{keV}$, and $a=-5.0233 \times 10^{-6}, b=1.8106 \times 10^{-7}, c=0.0088387 .1 \mathrm{kGy}$ in air is equivalent to $114 \mathrm{kR}$ so that Equation (2) at $40 \mathrm{keV}$ gives $\Phi_{\mathrm{ph}}=2.41 \times 10^{15}$ photons cm${ }^{-2}$, and at $120 \mathrm{keV}$ it gives $\Phi_{\mathrm{ph}}=2.24 \times 10^{15}$ photons $\mathrm{cm}^{-2}$, a small difference of about $7 \%$, The change in the fluence along with the large reduction in the energy absorption coefficient $\mu_{\text {en }}$ can provide a qualitative explanation of the energy dependence in Figure 11 and Figure 12. The attenuated photon fluence within $\Delta z$ is $\mu \Phi_{\mathrm{ph}} \Delta z$ where $\mu$ is the linear attenuation coefficient. The total energy

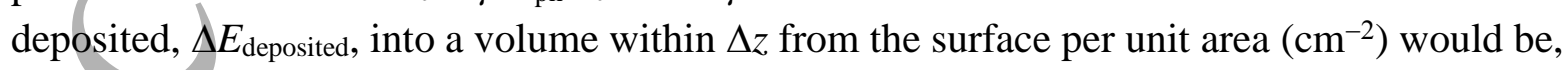

$$
\Delta E_{\text {deposited }}=\left(\mu_{\mathrm{en}} / \mu\right)\left(E \times 10^{3} \times 1.602 \times 10^{-19}\right)\left(\Phi_{\mathrm{ph}} \mu \Delta z\right) \quad\left[\mathrm{J} \mathrm{cm}^{-2}\right]
$$


in which the photon energy $E$ is kept in $\mathrm{keV}$. Using the photon fluence from Equation (2) and the appropriate values for $\mu_{\mathrm{en}}$ for the FA glass, within $20 \mu \mathrm{m}$, the deposited energy at $1 \mathrm{kGy}$ is $183 \mathrm{~J}$ $\mathrm{cm}^{-2}$ at $40 \mathrm{keV}$. It is smaller at $130 \mathrm{keV}$ with values of $18 \mathrm{~J} \mathrm{~cm}^{-2}$ for the photoelectron effect and $41.3 \mathrm{~J} \mathrm{~cm}^{-2}$ for incoherent scattering, a total energy deposition of $59 \mathrm{~J} \mathrm{~cm}^{-2}$, a decrease by a factor of 3 from 40 to $130 \mathrm{keV}$ at the same dose level. One can immediately see that the difference can qualitatively explain the reduction in the response with increasing photon energy. The deposited energy would change the concentration of structural defects created and hence the concentration of hole traps needed for the $\mathrm{Sm}^{3+}$ to $\mathrm{Sm}^{2+}$ conversion as previously discussed $[27,28,29,30,31,32,33,34]$. While the experimental results can be explained qualitatively from fundamental physical arguments, a detailed kinetic model would be needed that has multiple rate equations to predict the exact dependence, which is beyond the scope of this paper.

Ideally the detector medium should be tissue equivalent so that the measured deposited dose is similar to dose in tissues. Tissue equivalent detectors, such as diamond detectors $[18,50]$ are obviously very attractive in dosimetry. Unfortunately, Sm-valance conversion in glasses has only been seen in a few selected systems such as fluoroaluminate and fluotophosphate glasses, which are not tissue equivalent. Nonetheless, there is still much research interest in finding host material which are closer to being tissue equivalent.

The response of a dosimeter is generally a function of the radiation beam quality and the beam energy. For MRT purposes there is currently not a mutually agreed ideal energy for treatment purposes. Ideally, a dosimeter should not have a strong energy dependence. In practice however, when measuring an incident $\mathrm{x}$-ray energy range that varies over hundreds of kiloelectronvolts, the response of a dosimeter will require calibration. The energy range can differ widely depending on the application and the target, from small animal experiments, to the eventual treatment of human patients. What is of primary importance is the incident $\mathrm{x}$-ray energy range is sufficient to penetrate deep into the desired region of the tissue, the maximization of dose rate, the PVDR, and increasing the energy in order to reduce the overall dose that is deposited near the exterior of the subject, thus minimizing surface dose. Figure 12 indicates that a wide range of doses can be detected by $1 \%$ Sm-doped FA glass at multiple energies and is a suitable candidate for MRT purposes. Figure 13 indicates that at high doses (1 kGy) and lower energies such as $40 \mathrm{keV}$, the response $R$ is shown to be constant within the first $20 \mu \mathrm{m}$ of the Sm-doped FA glass samples, whereas for higher energies this does not play a significant role. The overall findings of this research illustrate that Sm-doped FA glasses, in comparison with Sm-doped FP glasses, are excellent candidates for highdose and high-resolution applications for MRT dosimetry purposes and the optimum doping level points to $1 \% \mathrm{Sm}$.

\section{Conclusions}

Sm-doped Fluoroaluminate and fluorophosphates glasses have been examined for the purposes of high-dose measurements in microbeam radiation therapy (MRT) dosimetry. These samples utilize the valence conversion of $\mathrm{Sm}^{3+}$ ions to $\mathrm{Sm}^{2+}$ after irradiation as a measurement of the dose delivered. These two ions yield distinct and separable PL signals that can be detected using a fluorescence (PL) confocal microscopy system designed to separate and detect the emission wavelengths of these two ions. These Sm-doped glass detector plates were then characterized for high-dose dosimetry by investigating the detector response (defined in terms of the relative 
intensities of the $\mathrm{Sm}^{2+}$ and $\mathrm{Sm}^{3+} \mathrm{PL}$ signals) as a function of the incident $\mathrm{x}$-ray energy (using monochromatic x-rays at the Canadian synchrotron) as well as the dose rate and the total dose incident on the detector (up to $2000 \mathrm{~Gy}$ in air). Each irradiation and subsequent measurements used a new but identical sample to avoid effects arising from accumulated dose.

It was found that the response of the irradiated glass plates did not show any dependence on the dose rate from $7 \times 10^{-3} \mathrm{~Gy}$ air/s to $5 \mathrm{~Gy}$ air/s at $50 \mathrm{keV}$ (monoenergetic $\mathrm{x}$-rays). Numerous samples were irradiated with doses up to $2 \times 10^{3} \mathrm{~Gy}$ air and it was shown that the detector glass plates can be suitably calibrated over the large dose range accessed in this work, following an exponential behavior of the form $R=R_{o}\left[1-\exp \left(-D / D_{o}\right)\right]$ from $40-120 \mathrm{keV}$. The constants $R_{o}$ and $D_{o}$ depend on the $\mathrm{x}$-ray energy and are listed in Table 1 . They are independent of the dose rate. Under low doses, the response vs. dose behavior was linear but falls below linearity at high doses.

The dependence of the response on the focal depth $d$ of the objective lens from the surface of the sample was also investigated. The optimum depth $d$ was determined to be $15-20 \mu \mathrm{m}$. This choice of $d$ was in good agreement with the vertical range determined by using a surface $\mathrm{Sm}^{2+}$-ion implanted FA glass plate. The choice of $d$ also minimized the photodarkening effect, which had to be included in analysis in works [32] that did not use an optical microscope and the signals had to cross the whole sample thickness of several millimeters. The lateral resolution of the optical readout technique for measuring the response of Sm-doped FA glass plates was determined to be under $1 \mu \mathrm{m}$. The readout technique was demonstrated to be capable of determining the microbeam profile at $50 \mathrm{keV}$ at the CLS.

Various glass sample compositions were irradiated in order to select the most suitable candidate for Sm-valence dosimetry. It was demonstrated that increasing the total number of Smdopants leads to a smaller $\mathrm{Sm}^{3+}$ to $\mathrm{Sm}^{2+}$ conversion, while lower concentrations lead to a spontaneous reconversion of $\mathrm{Sm}^{2+}$ to $\mathrm{Sm}^{3+}$ within hours after irradiation, which is not desirable. Further, photodarkening, which has a stronger presence in FP glasses, leads to complications in the readout method as a result of the change of absorbance in the same region as the emitted $\mathrm{Sm}^{3+}$ signals. The consideration of these factors lead to the choice of $1 \% \mathrm{Sm}$-doped FA as probably the most suitable Sm-doped glass. Overall, 1\% Sm-doped FA glass has shown excellent conversion of $\mathrm{Sm}^{3+}$ to $\mathrm{Sm}^{2+}$ over a wide range of doses and energies and has shown no evidence of any dose rate dependence.

\section{Acknowledgements}

We thank both the Natural Sciences and Engineering Research Council of Canada (NSERC) Discovery Grants Program and the New Zealand Ministry of Business, Innovation, and Employment. This work was also supported by The Royal Society (London) through an International Exchange Award (IE160035) and by the UK Engineering and Physical Sciences Research Council (EPSRC) Grant No. EP/N020057/2. We would like to thank Albert Hanson and Fred Geisler for their work involving the simulations of microbeams in FA glass with the MCNP radiation transport computer code. We would also like to thank Chris Varoy for his previous work on FA and FP glass samples that lead to the refinement of the glass making process. Research described in this paper was performed at the Canadian Light Source, which is supported by the Canada/Foundation for Innovation, Natural Sciences and Engineering Research Council of 
Canada, the University of Saskatchewan, the Government of Saskatchewan, Western Economic Diversification Canada, the National Research Council Canada, and the Canadian Institutes of Health Research.

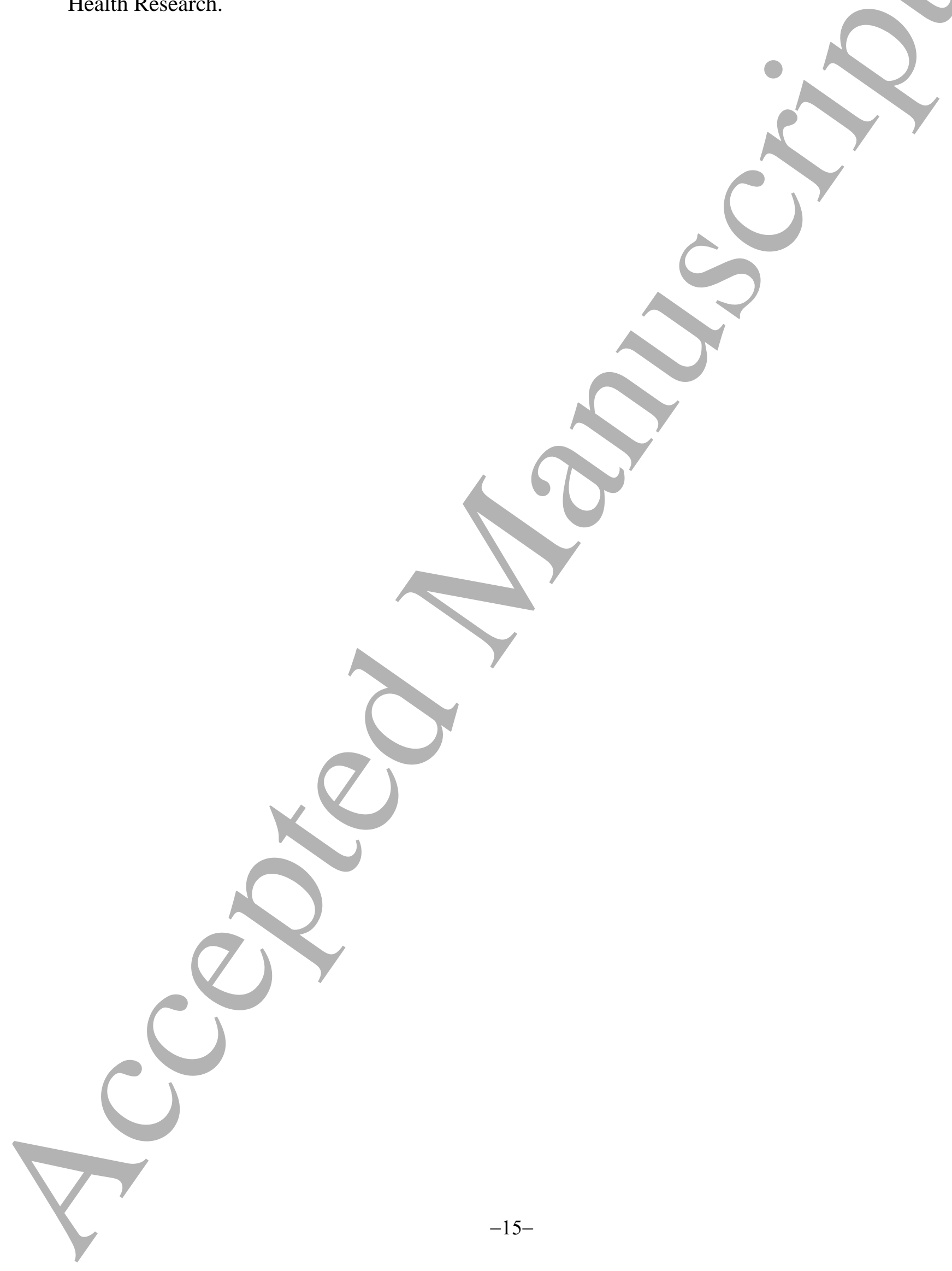




\section{Figures and Tables}

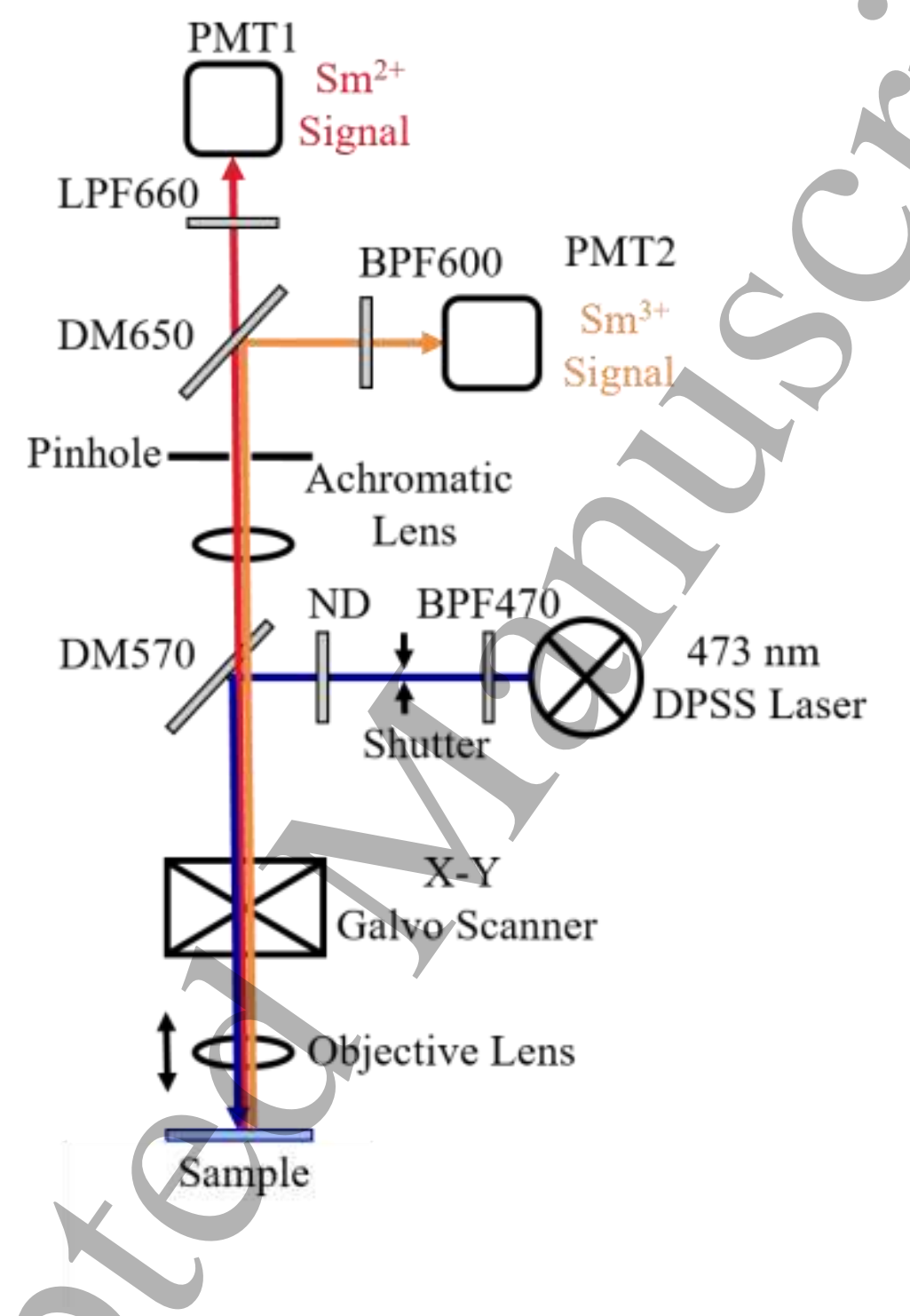

Figure 1 An illustration of the confocal microscopy set up used in measuring Sm-doped glass plates. The excitation source is a $473 \mathrm{~nm}$ diode-pumped solid-state (DPSS) laser, which has an adjustable focal depth within the glass samples and an intensity that can be modified through the use of neutral density filters (ND). Emission from $\mathrm{Sm}^{3+}$ and $\mathrm{Sm}^{2+}$ ions are filtered through dichroic mirrors (DM), and then collected simultaneously by two separate photomultiplier tubes tuned to the $\mathrm{Sm}^{3+}$ and $\mathrm{Sm}^{2+}$ wavelengths through the use of band-pass (BPF) and long-pass filters (LPF). The detection ranges of these PMTs are given in Figure 2 . The available objective are $10 \times / 0.3 \mathrm{NA}$ (Meopta) and 20×/0.75NA (Nikon) and the available pinhole sizes are 200, 100, and $50 \mu \mathrm{m}$. 


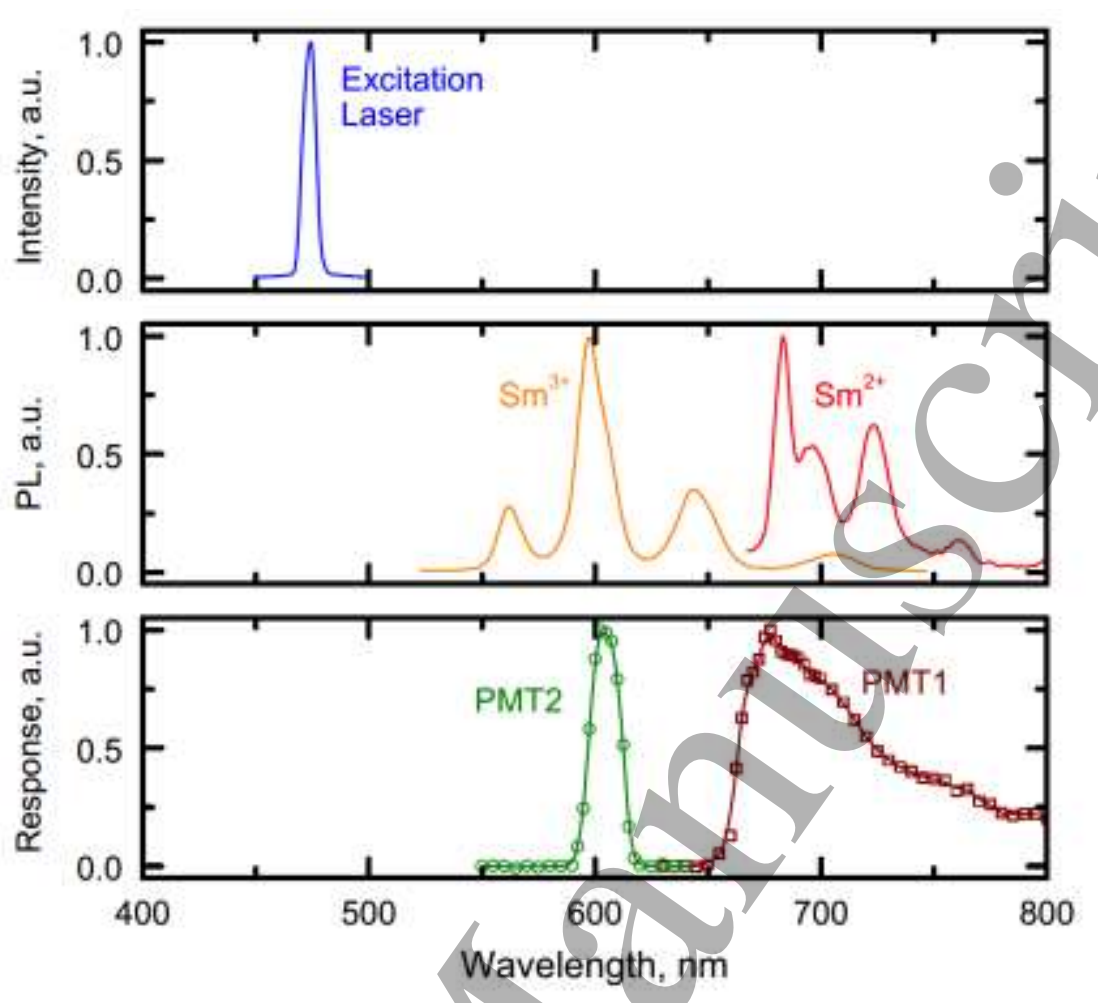

Figure 2 Upper figure shows the excitation spectrum centered at $473 \mathrm{~nm}$. The middle figures show the PL spectra from $\mathrm{Sm}^{3+}$ and $\mathrm{Sm}^{2+}$ ions. The lower figure shows the spectral response of the two photomultiplier tubes with their respective filters; long-pass for PMT1 and band-pass for PMT2. The detection ranges are $595-615 \mathrm{~nm}$ (FWHM) for PMT2 $\left(\mathrm{Sm}^{3+}\right)$ and $660-720 \mathrm{~nm}(\mathrm{FWHM})$ for PMT1 $\left(\mathrm{Sm}^{2+}\right)$. 


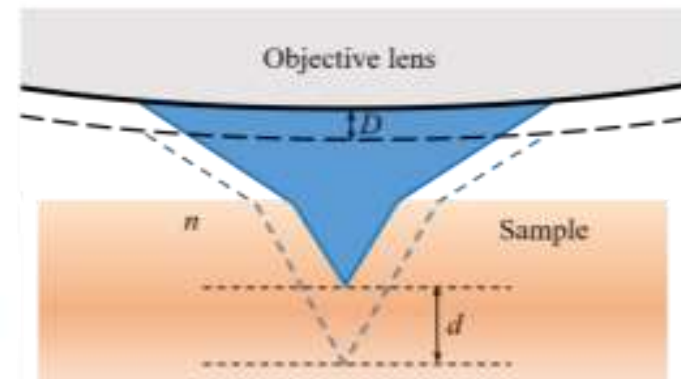

(a)

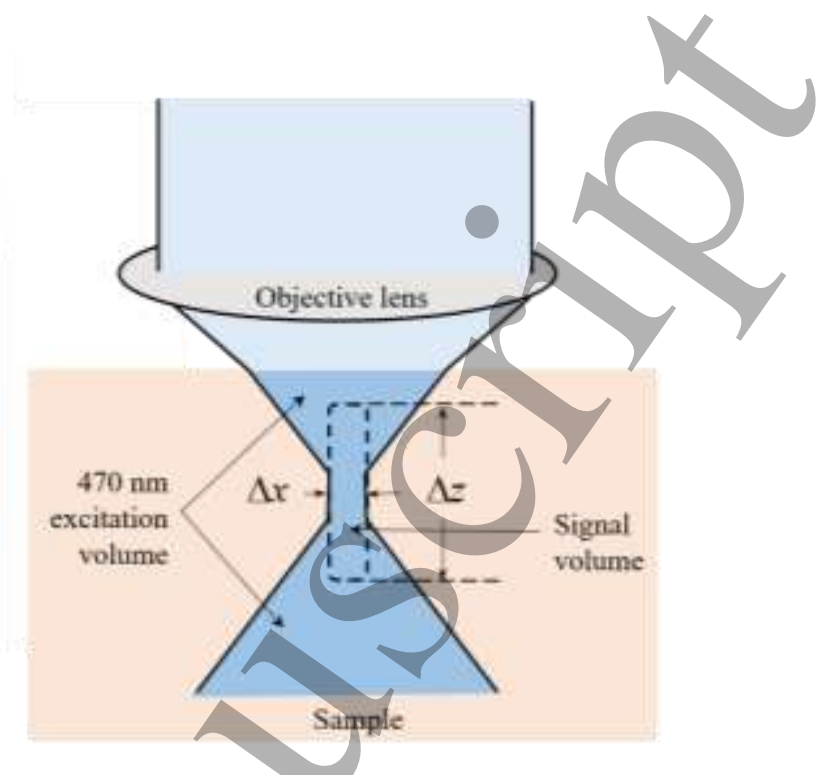

(b)

Figure 3 (a) Schematic illustration of the motion of the objective lens and the movement of the focal point inside the sample. The objective lens moves by $D$ and the focal point by $d$ and the two are related through the refractive index. (b) The $470 \mathrm{~nm}$ excitation volume inside the sample defined by the objective lens is shown as shaded in darker blue. The luminescence signals within the width of the focal point and the vertical range $\Delta z$ are measured. 


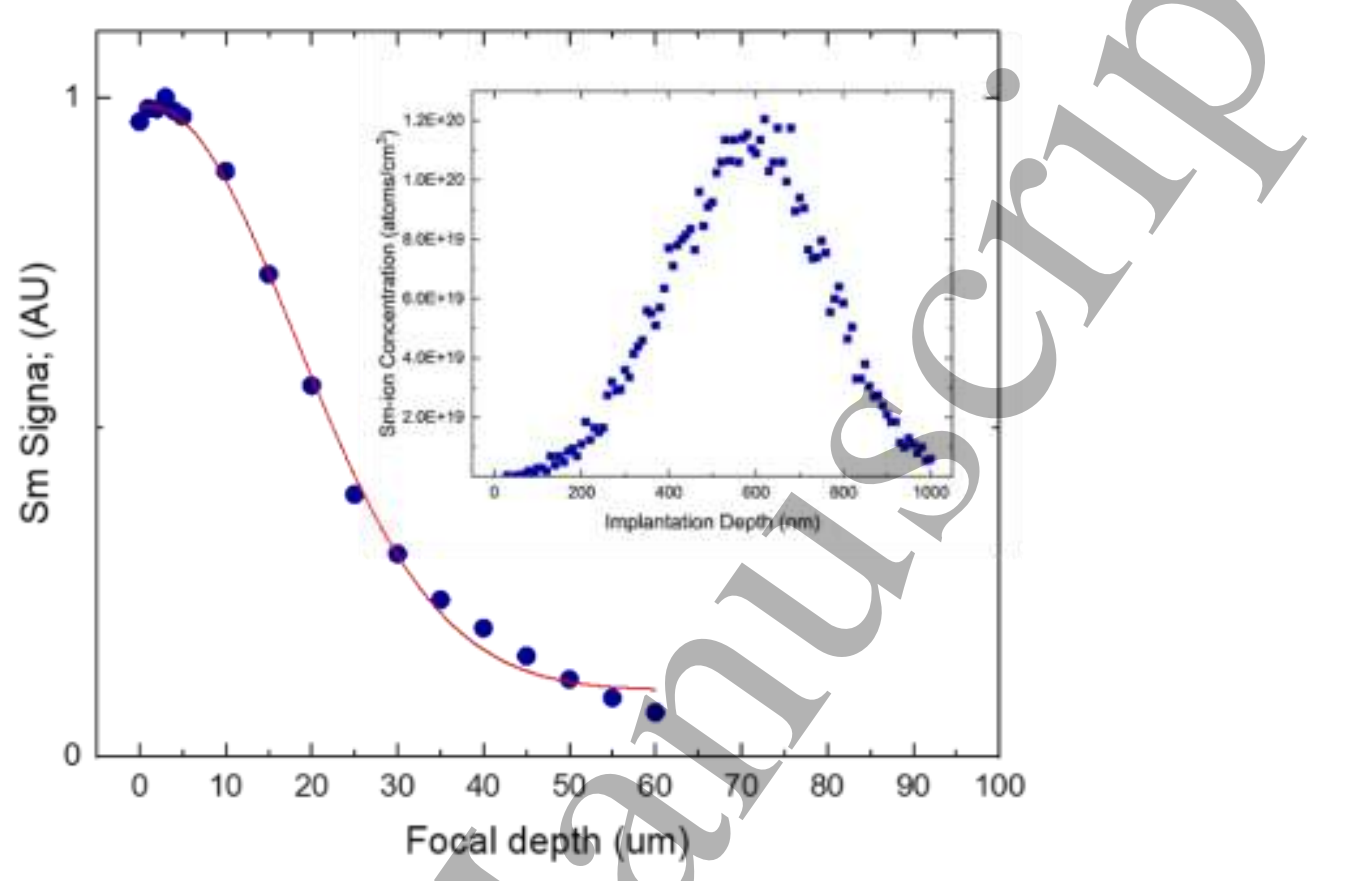

Figure 4 The $\mathrm{PL}\left(\mathrm{Sm}^{2+}\right)$ signal from ion-implanted $\mathrm{Sm}^{2+}$ ions within $1 \mu \mathrm{m}$ from the surface of a FA glass plate. Ion implantation peak is at $0.60 \mu \mathrm{m}$ as shown in the insert [35]. The solid line is the best Gaussian curve fit with a half width at half maximum that is $21 \mu \mathrm{m}$ 
Figure 5 The PL signal vs distance from the sample surface. The blue dots represent $\mathrm{Sm}^{3+}$ values measured in $1 \%$ bulk Sm-doped FA glass and the red line is calculated from the fitted Gaussian signal from an ion implanted sample where $\mathrm{Sm}^{2+}$ ions reside within a depth of $600 \mathrm{~nm}$, as shown in Figure 4, integrated from $10 \mu \mathrm{m}$ outside the glass surface to $60 \mu \mathrm{m}$ within the sample. 

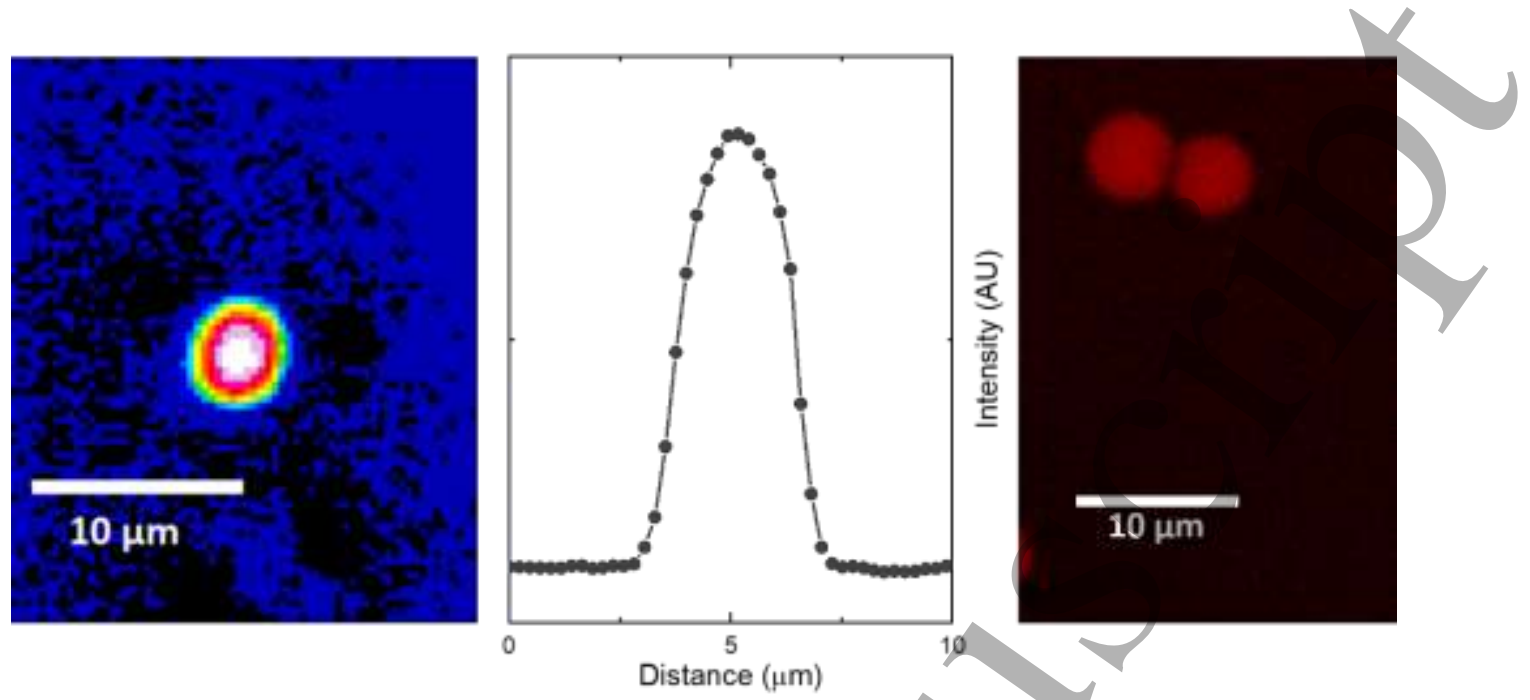

Figure 6 (left) An image of $4 \mu \mathrm{m}$ fluorescent microsphere which was acquired using the confocal fluorescence microscopy readout system used in this work with the $20 \times$ objective. (center) the measured 1D profile of the 2D imaged microsphere from confocal fluorescence microscopy. (right) $4 \mu \mathrm{m}$ fluorescent microspheres as measured by a 2-photon confocal microscope. 


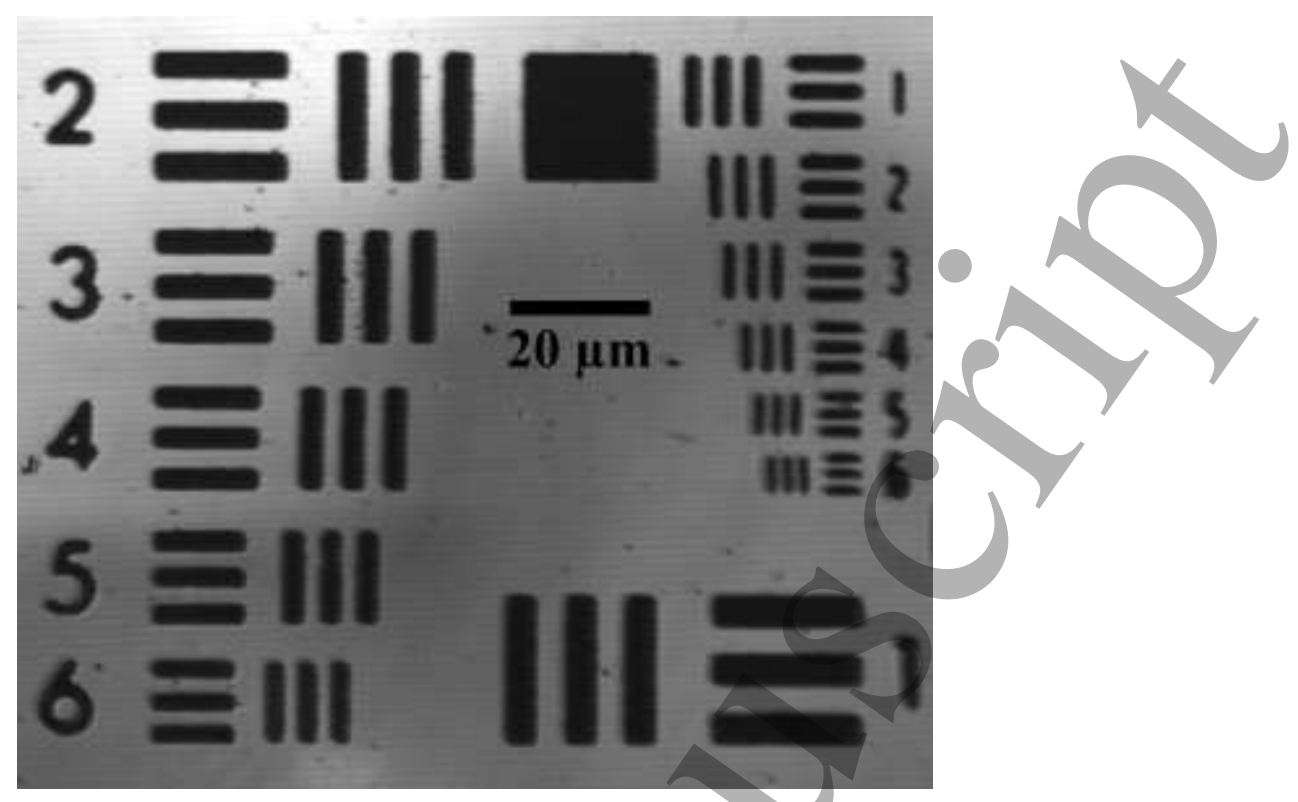

Figure 7 Image of a 1951 USAF resolution plate collected through the reflection of the incident laser on the target surface through a 20x objective lens. This image shows group 6 and 7 of the resolution plate where the smallest line widths are $4.38 \mu \mathrm{m}$ and $2.19 \mu \mathrm{m}$, respectively. 

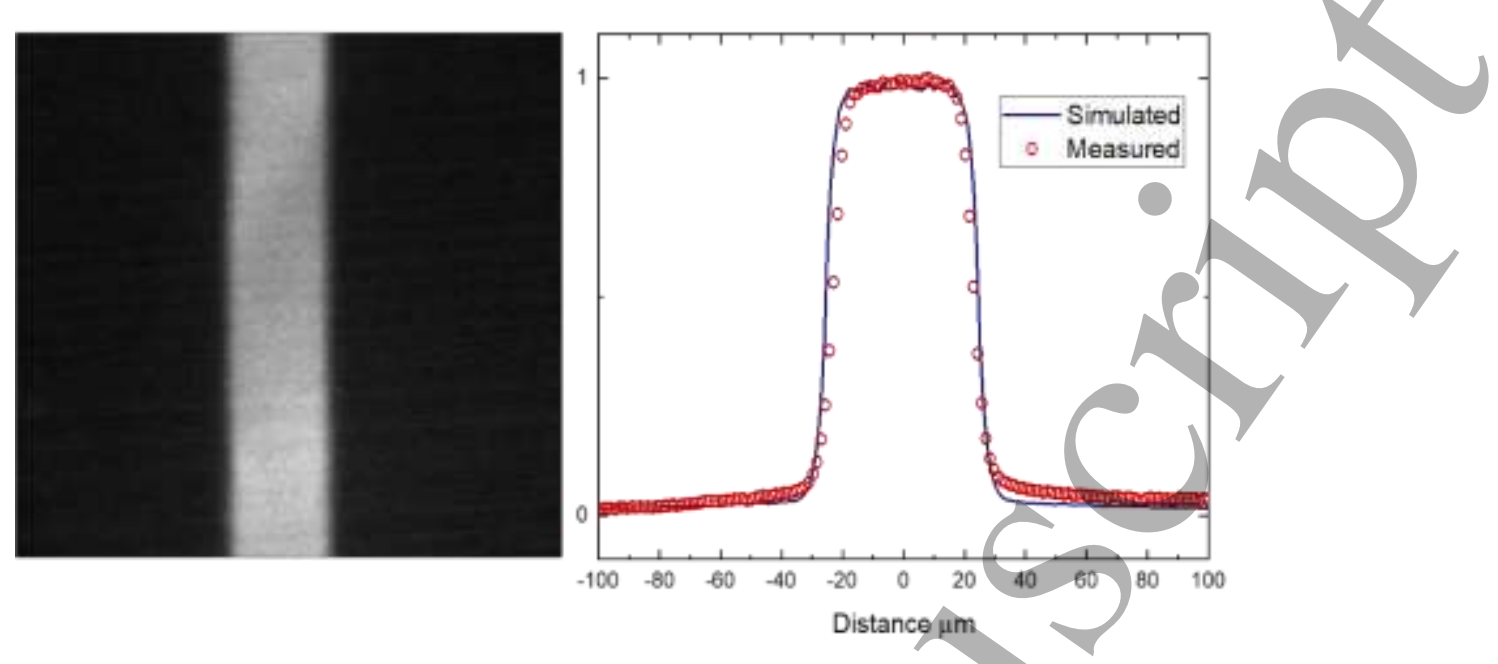

Figure 8 (left) 2D image of a single irradiated microbeam on a 1\% Sm-doped FA glass slide performed at the CLS. The incident $\mathrm{x}$-ray energy was selected to be $50 \mathrm{keV}$ and the total dose delivered was $200 \mathrm{~Gy}$ air prior to passing through the collimator. The collimator has a slit width of $50 \mu \mathrm{m}$ and the peaks are separated by a distance of $400 \mu \mathrm{m}$, center to center. (right) Plotted 1D profile of shown $2 \mathrm{D}$ image. The red circles indicate measured values of the microbeam profile and the blue lines indicate the modeled beamshape through Monte Carlo simulations [43] with the MCNP [42] radiation transport computer code of monochromatic $50 \mathrm{keV}$ x-rays incident on $1 \%$ Sm-doped FA glass. These measured profiles agree/ well with simulations and the energy dependence on the microbeam shape will be discussed in greater detail in an upcoming paper. 


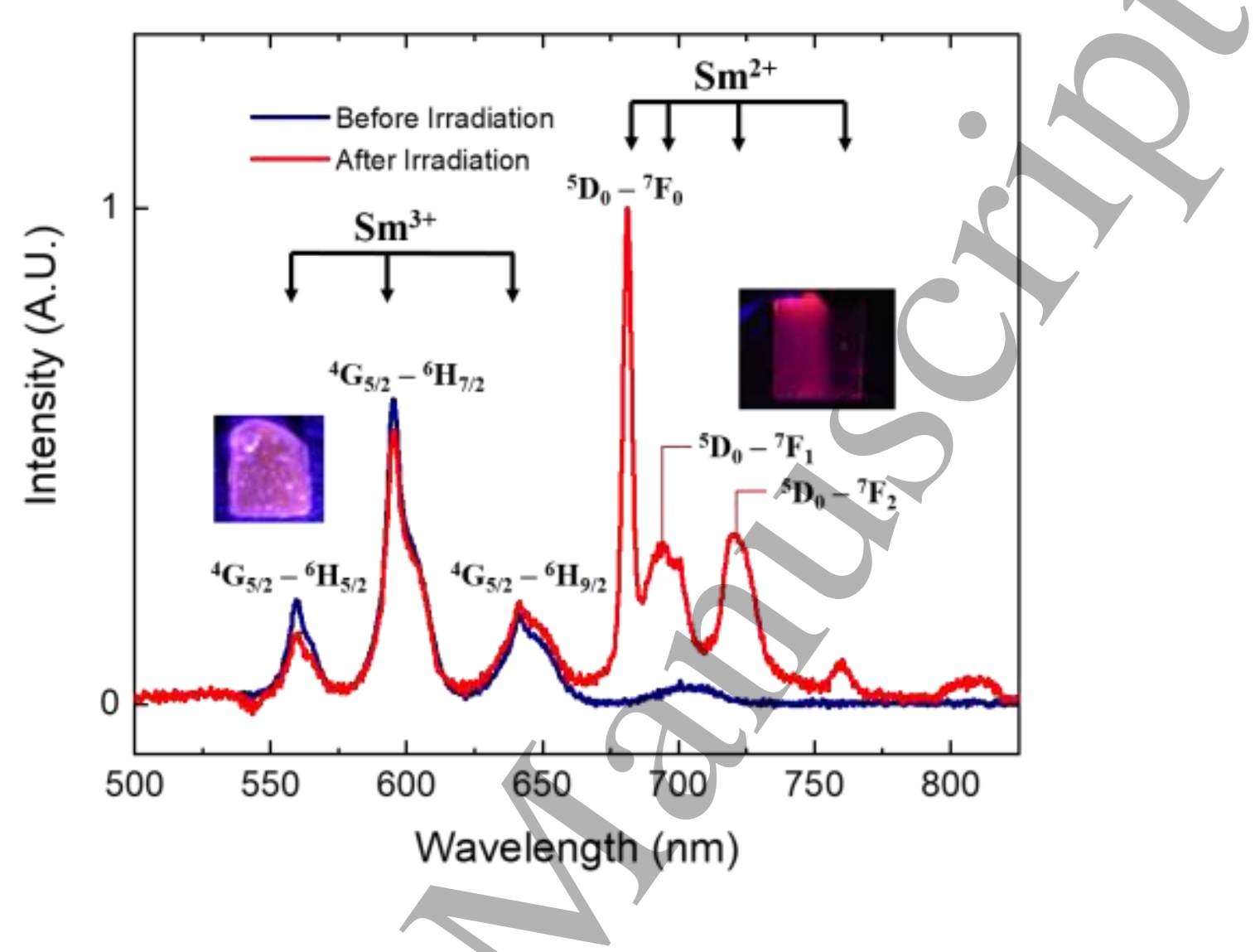

Figure 9 PL spectra of $1 \%$ Sm doped FA glass before and after irradiation using a FAXITRON xray cabinet. The emission spectra of $\mathrm{Sm}^{3+}$ and $\mathrm{Sm}^{2+}$ are shown. The sample has been irradiated with an approximate dose of 1500 Gyair. The left photo is the unexposed sample under UV excitation. The right photo is a sample that has been exposed a large dose. The image of red luminescence from the exposed glass was taken using a filter that suppressed wavelengths below $660 \mathrm{~nm}$. 


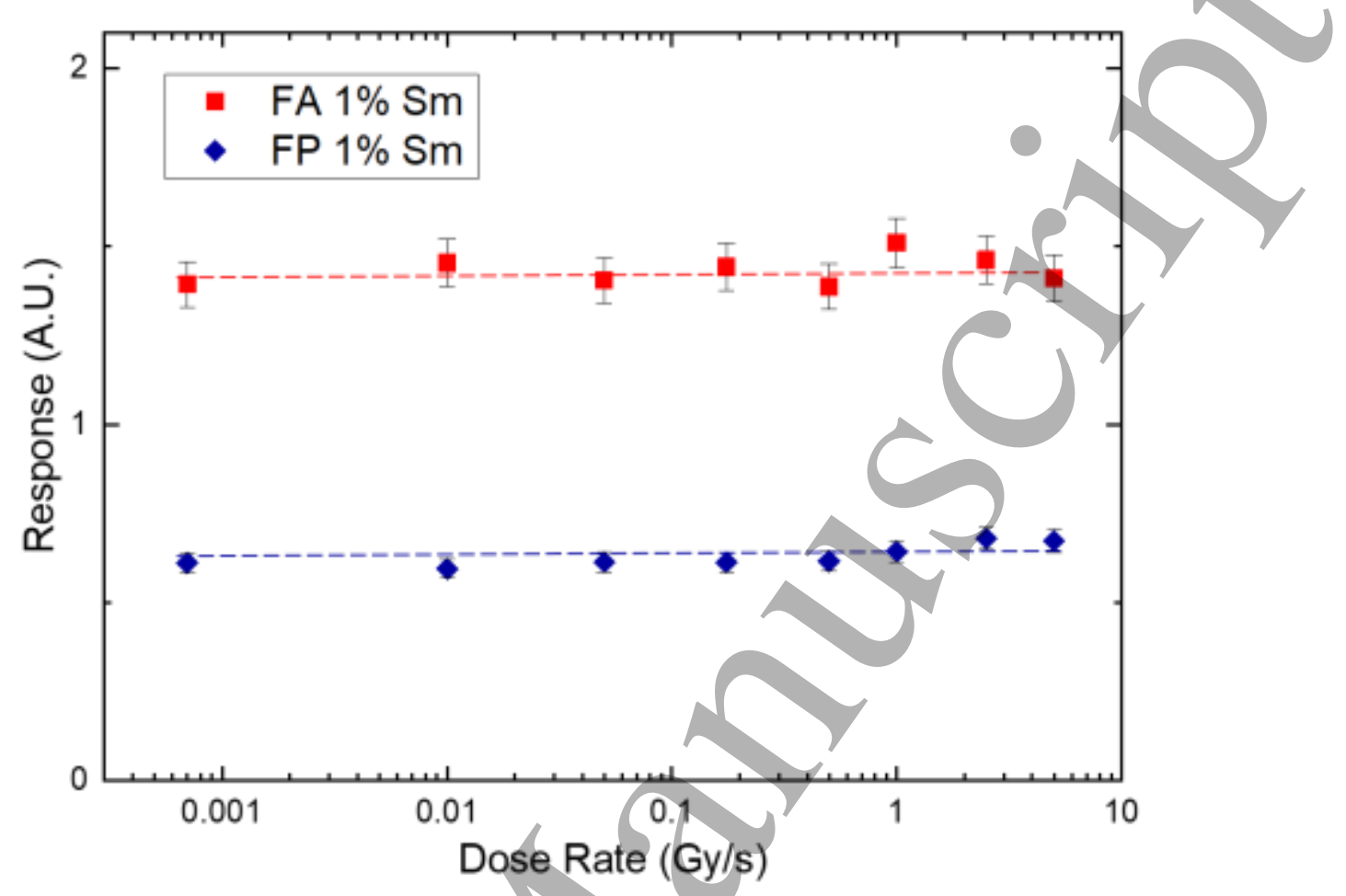

Figure 10 Response values (Ratio of PL( $\left.\mathrm{Sm}^{2+}\right) / \mathrm{PL}\left(\mathrm{Sm}^{3+}\right)$ ) of $1 \%$ Sm doped FA and FP glasses as a function of delivered dose rate to the sample. All samples were irradiated with a total dose of $200 \mathrm{~Gy}$ in air as measured by an ionization chamber with incident $\mathrm{x}$-ray energy of $50 \mathrm{keV}$. 


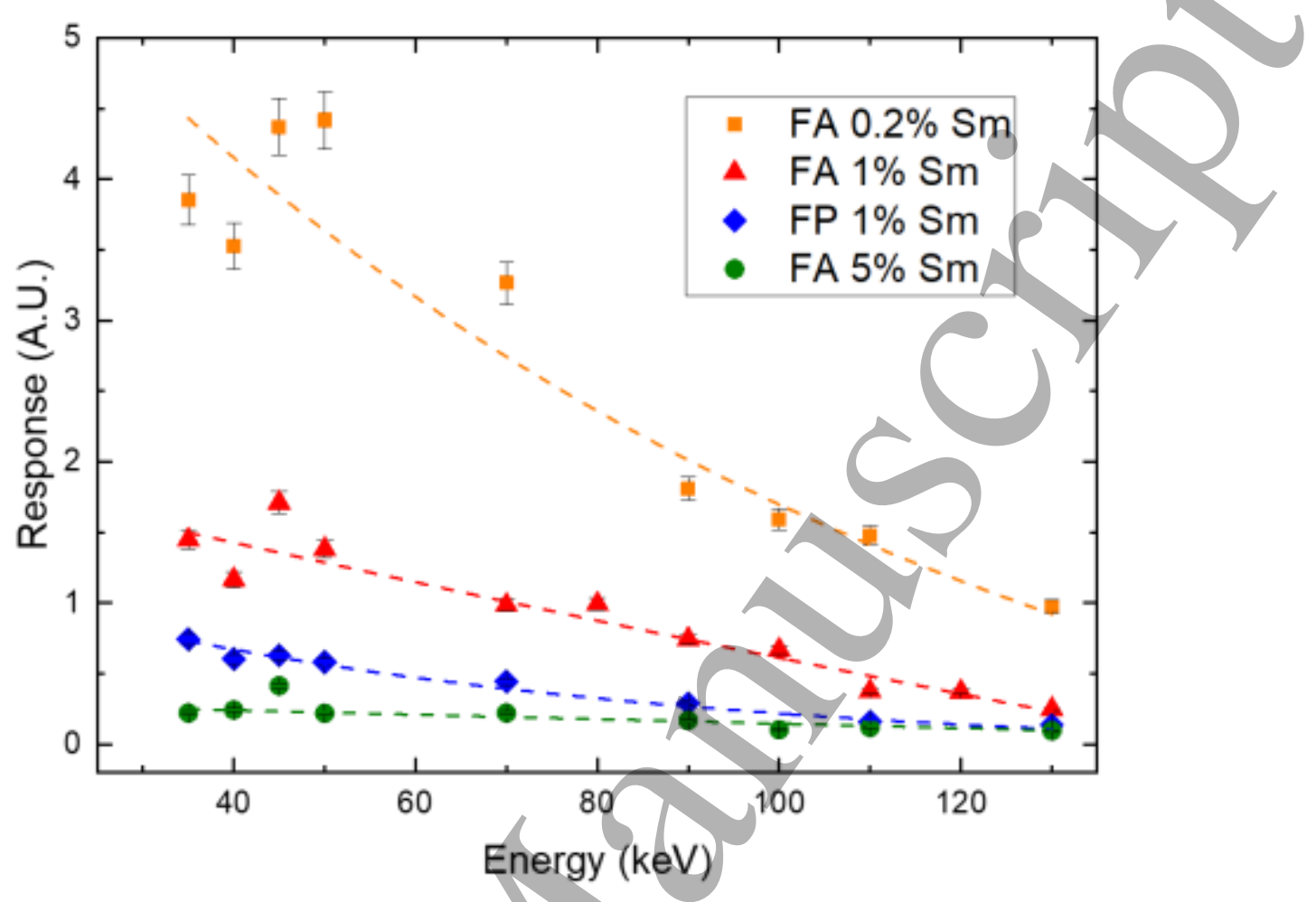

Figure 11 Response values (Ratio of $\mathrm{PL}\left(\mathrm{Sm}^{2+}\right) / \mathrm{PL}\left(\mathrm{Sm}^{3+}\right)$ ) of Sm doped FA and FP glasses. All samples were irradiated with a dose of 200 Gy in air as measured by an ionization chamber and the dose rate was set to be $175 \mathrm{mGy} / \mathrm{s}$. For all dopant concentrations and host glass materials, the response values decrease as a function of energy with the range of 35 to $130 \mathrm{keV}$. As the dopant concentration is increased the overall conversion of $\mathrm{Sm}^{3+}$ to $\mathrm{Sm}^{2+}$ decreases. 


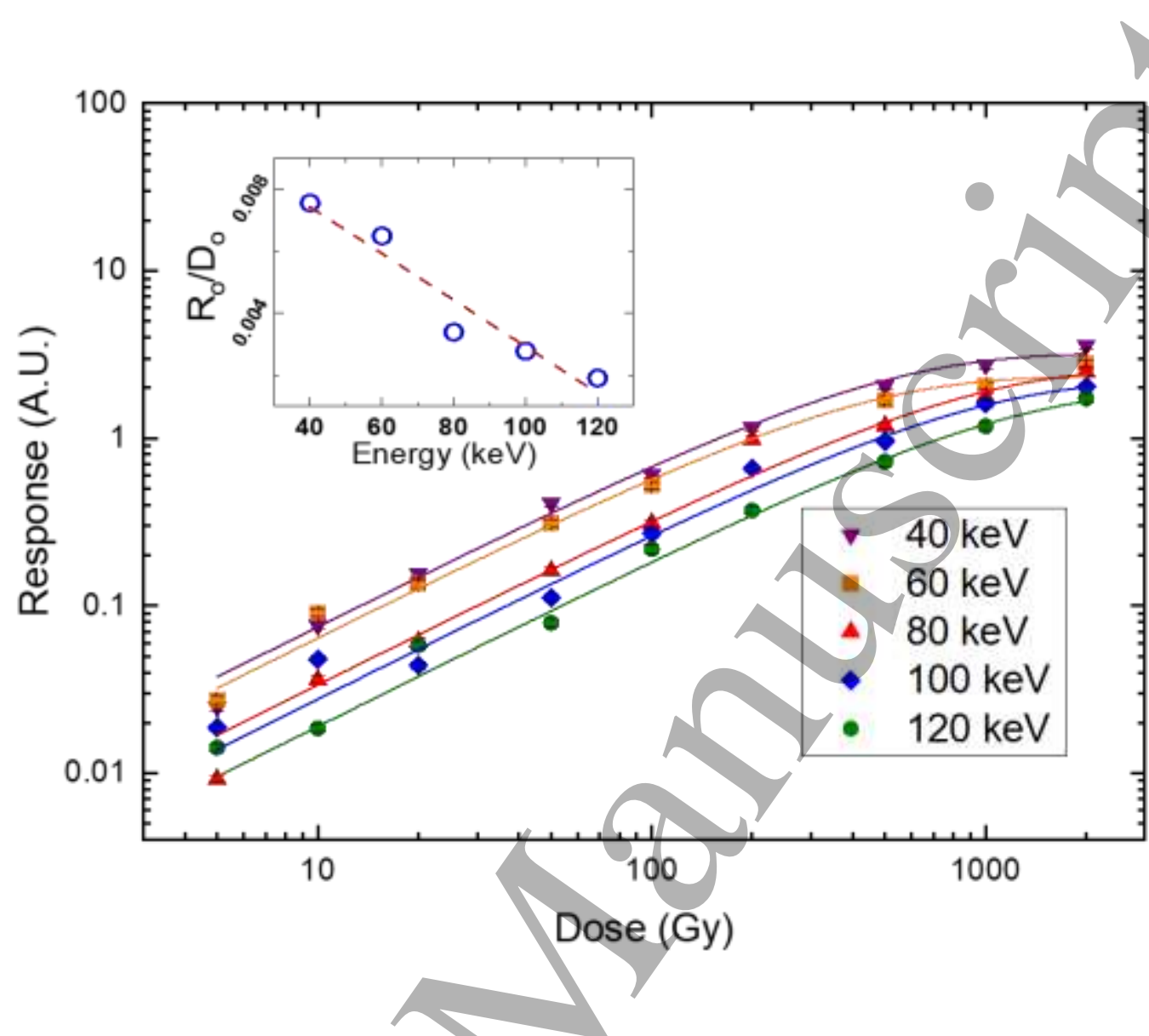

Figure 12 Response values (Ratio of $\mathrm{PL}\left(\mathrm{Sm}^{2+}\right) / \mathrm{PL}\left(\mathrm{Sm}^{3+}\right)$ ) of $1 \% \mathrm{Sm}$ doped FA glass at multiple energies from 5 - $2000 \mathrm{~Gy}$. Exponential fits are shown in Table 1. Each dot represents an individual piece of glass sample, that is, the dose shown is not cumulative. Equation for fitted line in the insert where $R_{o} / D_{o}$ vs. $E$ is plotted is $\left(R_{o} / D_{o}\right)=(0.01043 \pm 0.001)-\left(7.5 \times 10^{-5} \pm 1.18 \times 10^{-5}\right) E$. 


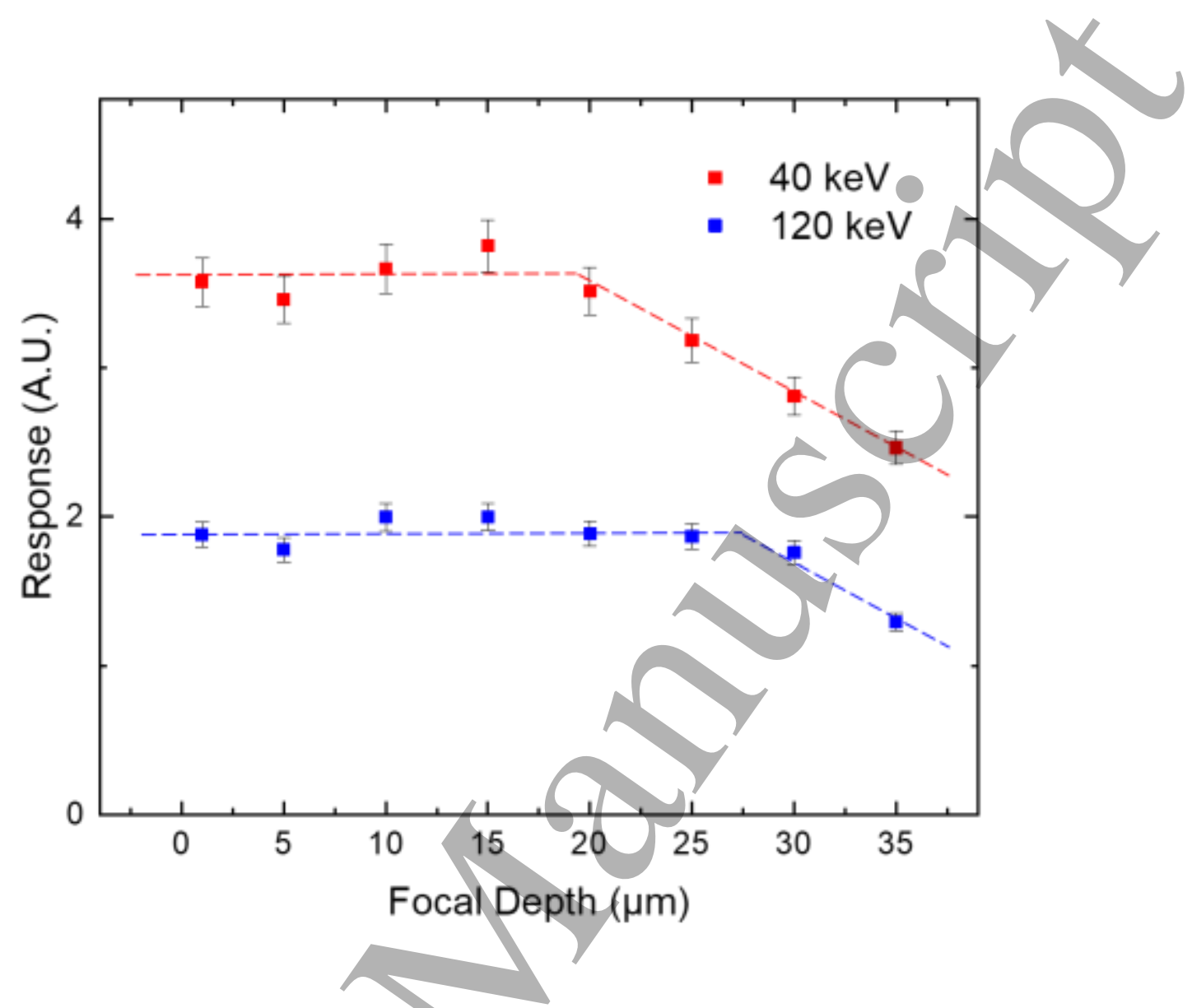

Figure 13 Response of irradiated 1\% Sm FA glasses as the focal depth of the incident laser in the fluorescent confocal microscopy (shown in Figure 1) is modified at two different energies, $40 \mathrm{keV}$ and $120 \mathrm{keV}$. The total dose delivered to each sample is $1 \mathrm{kGy}$ using a monochromatic $\mathrm{x}$-ray energy synchrotron source. As the incident $\mathrm{x}$-ray energy is increased the conversion of $\mathrm{Sm}^{3+}$ ions to $\mathrm{Sm}^{2+}$ is constant within a larger volume in the glass material. The vertical axis is the same for both. 


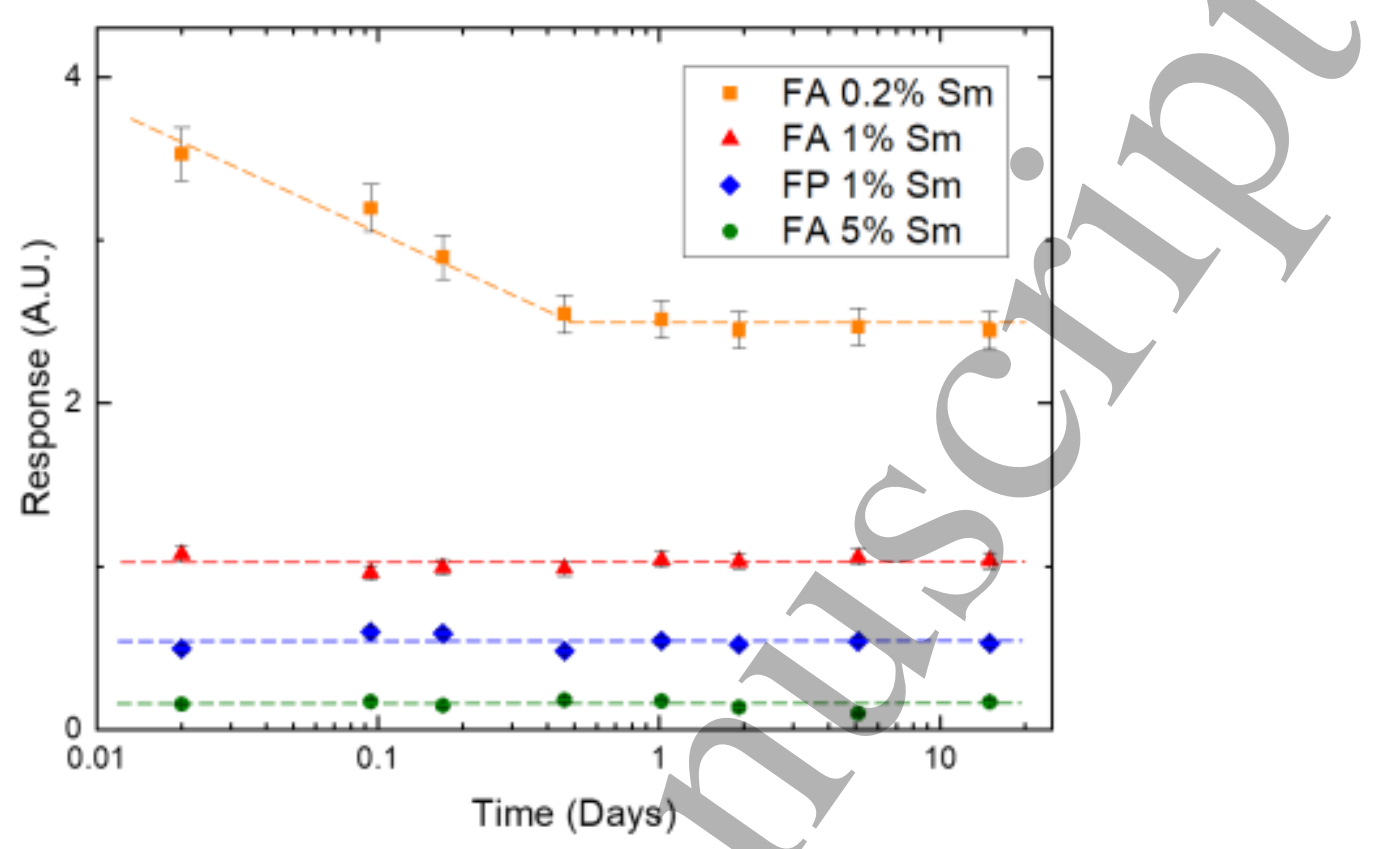

Figure 14 Stability of varying Sm-dopant concentrations and host glass materials over time. All samples have been irradiated with an approximate dose of 500 Gy using a FAXITRON x-ray cabinet. Each data point represents an individual sample. It appears as though lower Sm-dopant concentrations are less stable after irradiation, although all samples appear to be stable after approximately 1 day.

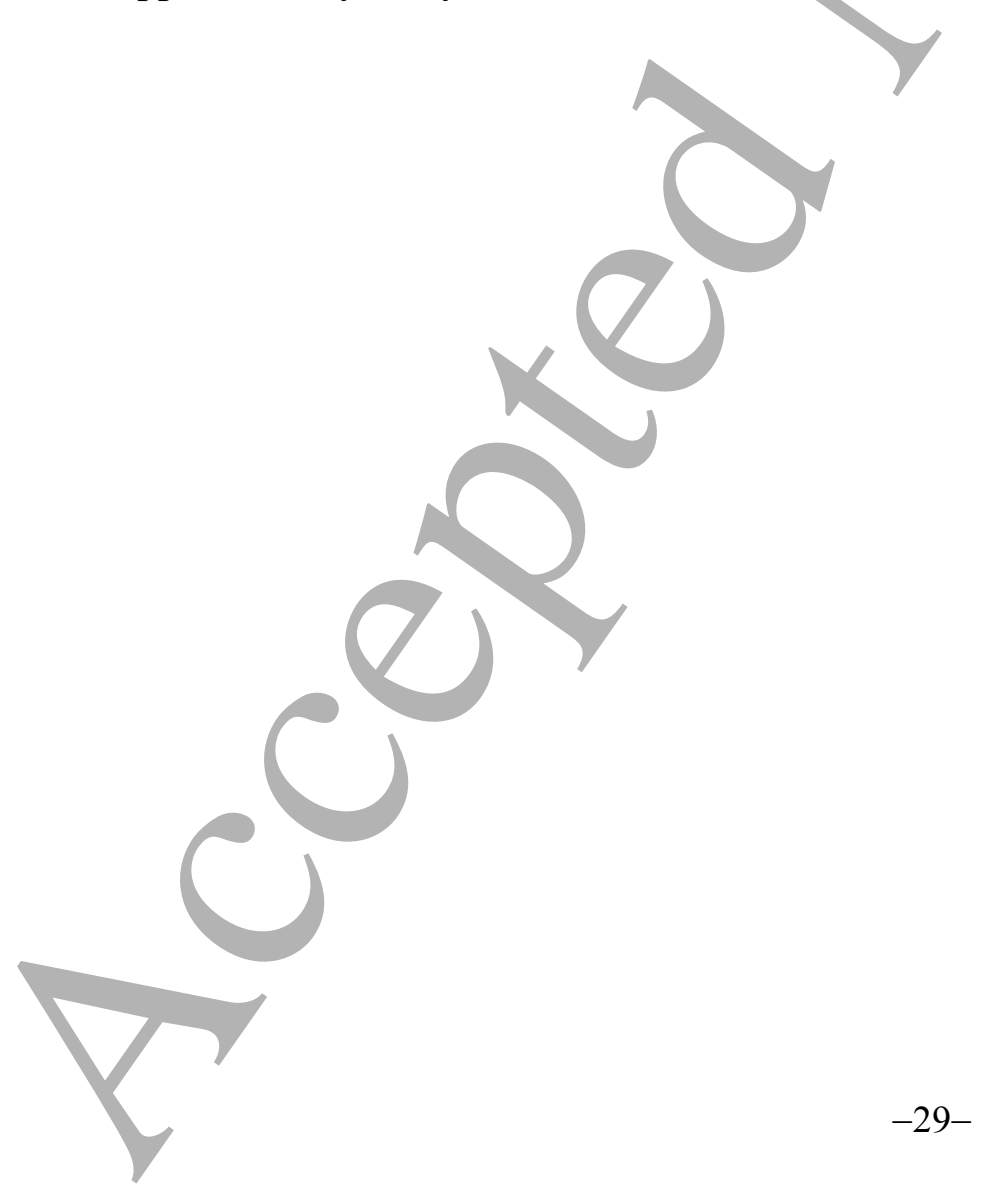


Table 1 The best fits of $R=R_{o}\left[1-\exp \left(-D / D_{o}\right)\right]$ to the experimental data in Figure 12. $R^{2}$ is the so-called $R$-squared goodness of fit or the coefficient of determination.

\begin{tabular}{|c|c|c|c|}
\hline $\begin{array}{c}\text { Energy } \\
(\mathrm{keV})\end{array}$ & $R_{o}$ & $D_{o}(\mathrm{~Gy})$ & $\begin{array}{c}R^{2} \\
\text { Exponential } \\
\text { fit }\end{array}$ \\
\hline 120 & $1.94 \pm 0.22$ & $1014 \pm 156$ & 0.9902 \\
\hline 100 & $2.19 \pm 0.27$ & $789 \pm 142$ & 0.9723 \\
\hline 80 & $2.62 \pm 0.32$ & $773 \pm 128$ & 0.9752 \\
\hline 60 & $2.33 \pm 0.18$ & $359 \pm 41.3$ & 0.9840 \\
\hline 40 & $3.20 \pm 0.25$ & $423 \pm 43.8$ & 0.9860 \\
\hline
\end{tabular}




\section{References}

${ }^{1}$ G. Blasse and B.C. Grabmaier, Luminescent Materials, Springer-Verlag, Heidelberg, 1997

${ }^{2}$ L. Boetter-Jensen, S.W.S. McKeever, A.G. Wintle, Optically Stimulated Luminescence Dosimetry, Elsevier Science B.V. Amsterdam, 2003

${ }^{3}$ E G Yukihara and S W S McKeever, Optically stimulated luminescence (OSL) dosimetry in medicine, Phys. Med. Biol. 53 R351 - R379 (2008)

${ }^{4}$ E.G. Yukihara and S.W.S. McKeever, Optically Stimulated Luminscence: Fundamentals and Applications , John Wiley and Sons Ltd, Chichester, UK, 2011 (ISBN: 978-0-470-69725-2)

${ }^{5}$ E. G.Yukihara, S. W.S.McKeever, M. S.Akselrod, State of art: Optically stimulated luminescence dosimetry - Frontiers of future research, Radiation Measurements, 71, 15-24 (2014)

${ }^{6}$ A. Edgar, Ch: 38, Luminescent Materials in S.Kasap and P. Capper (eds), Springer Handbook of Electronic and Photonics Materials, Second Edition, Springer International Publishing AG, Cham (Switzerland), 2017

${ }^{7}$ R. Chen and V. Pagonis, Advances In Physics And Applications of Optically And Thermally Stimulated Luminescence, World Scientific, Singapore, 2019

${ }^{8}$ D. N. Slatkin, F. A. Dilmanian, P. Spanne, M. Sandborg, Microbeam radiation therapy. Med. Phys. 19, 1395-400 (1992)

${ }^{9}$ R. Lewis, Medical applications of synchrotron radiation x-rays (topical review), Phys. Med. Biol. 421213 - 1243 (1997), and references therein

${ }^{10}$ H. Blattmann, J. Gebbers, E. Bräuer-Krisch, A. Bravin, G. Le Duc, W. Burkard, M. Di Michiel, V. Djonov, D. N. Slatkin, J. Stepanek, J. A. Laissure, Applications of synchrotron X-rays to radiotherapy. Nucl. Instrum. Methods Phys. Res., Sect. A. 548, 17-22 (2005)

${ }^{11}$ A. Dilmanian, Z. Zhong, T. Bacarian, H. Benveniste, P. Romanelli, R. Wang, J. Welwart, T. Yuasa, E. M. Rosen, D. J. Anschel, Interlaced xray microplanar beams: A radiosurgery approach with clinical potential. Proc. Natl. Acad. Sci. U.S.A. 103 9709-14 (2006)

${ }^{12}$ C. Crosbie, R. L. Anderson, K. Rothkamm, C. M. Restall, L. Cann, S. Ruwanpura, S. Meachem, N. Yagi, I. Svalbe, R. A. Lewis, B. R. G. Williams, P. A. W. Rogers, Tumor cell response to synchrotron microbeam radiation therapy differs markedly from cells in normal tissues. Int. J. Radiat. Oncol. Biol. Phys. 77, 886-94 (2010)

${ }^{13}$ E. Bräuer-Krisch, R. Serduc, E. A. Siegbahn, G. Le Duc, Y. Prezado, A. Bravin, H. Blattmann, J. A. Laissue, Effects of pulsed, spatially fractionated, microscopic synchrotron x-ray beams on normal and tumoral brain tissue. Mutat. Res. Mutat. Res. 704, 160-6 (2010)

${ }^{14}$ M.A. Grotzera, E. Schültke, E. Bräuer-Krisch, J.A. Laissue, Microbeam radiation therapy: Clinical perspectives, Physica Merdica, 31, 564 - 567 (2015)

15 J C Crosbie, I Svalbe, S M Midgle, N Yagi, P A W Rogers and R A Lewis, A method of dosimetry for synchrotron microbeam radiation therapy using radiochromic films of different sensitivity, Phys. Med. Biol. 53, 6861 (2008)

${ }^{16}$ E. Bräuer-Krisch, A. Rosenfeld, M. Lerch, M. Petasecca, M. Akselrod, J. Sykora, J. Bartz, M. Ptaszkiewicz, P. Olko, A. Berg, M. Wieland, S. Doran, T. Brochard, A. Kamlowski, G. Cellere, 
A. Paccagnella, E. A. Siegbahn, Y. Prezado, I. Martinez-Rovira, A. Bravin, L. Dusseau, P. Berkvens, Potential high resolution dosimeters for MRT. AIP Conf. Proc. 1266, 89-97 (2010)

${ }^{17}$ M Petasecca, A Cullen, I Fudulia A Espinoza, C Porumb, C Stantona, A H Aldosari, E BräuerKrisch, H Requardt, A Bravin, X-Tream: a novel dosimetry system for Synchrotron Microbeam Radiation Therapy, J. Instrum. (IOP) 7, P07022 (2012) (doi:10.1088/1748-0221/7/07/P07022)

18 Jayde Livingstone, Andrew W. Stevenson, Duncan J. Butler, Daniel Häusermann, JeanFrançois Adam, Characterization of a synthetic single crystal diamond detector for dosimetry in spatially fractionated synchrotron x-ray fields, Med. Phys., 43, 4283-4293 (2016)

19 J. A Davis, J. R Paino, A. Dipuglia, M. Cameron, R. Siegele , Z. Pastuovic, M. Petasecca, V. L Perevertaylo, A. B Rosenfeld, and M. L F Lerch, Biomed. Phys. Eng. Express 4044002 (2018)

${ }^{20}$ J. Archer, E. Li, J. Davis, M. Cameron, A. Rosenfeld, M. Lerch, High spatial resolution scintillator dosimetry of synchrotron microbeams. Scientific Reports. 9, 6873 (2019)

${ }^{21}$ E.G.Yukihara, V.H.Whitley, S.W.S.McKeever, A.E.Akselrod, M.S.Akselrod, Effect of highdose irradiation on the optically stimulated luminescence of $\mathrm{Al}_{2} \mathrm{O}_{3}: \mathrm{C}$, Radiation Measurements 38, $317-330$ (2004)

${ }^{22}$ D. L. Griscom, E. J. Friebele, K. J. Long, J. W. Fleming, Fundamental defect centers in glass: Electron spin resonance and optical absorption studies of irradiated phosphorus-doped silica glass and optical fibers. J. Appl. Phys. 54, 3743-62 (1983)

${ }^{23}$ K. Miura, J. Qiu, S. Fujiwara, S. Sakaguchi, K. Hirao, Three-dimensional optical memory with rewriteable and ultrahigh density using the valence-state change of samarium ions. Appl. Phys.Lett. 80, 2263-5 (2002)

${ }^{24}$ E. Malchukova, B. Boizot, G. Petite, D. Ghaleb, Optical properties and valence state of Sm ions in aluminoborosilicate glass under $\beta$-irradiation. J. Non-Cryst. Solids. 353, 2397-402 (2007)

${ }^{25}$ A. Nag, T. Kutty, The light induced valence change of europium in $\mathrm{Sr}_{2} \mathrm{SiO}_{4}$ : Eu involving transient crystal structure. J. Mater. Chem. 14, 1598-1604 (2004)

${ }^{26}$ H. Luo, A. Bos, P. Dorenbos, Controlled electron-hole trapping and detrapping process in $\mathrm{GdAlO}_{3}$ by valence band engineering. J. Phys. Chem. 120, 5916-25 (2016)

${ }^{27}$ S. Vahedi, G. Okada, C. Koughia, R. Sammynaiken, A. Edgar, S. Kasap, ESR study of samarium doped fluorophosphate glasses for high-dose, high-resolution dosimetry. Optical Materials Express. 4, 1244-56 (2014)

${ }^{28}$ G. Okada, J. Ueda, S. Tanabe, G. Belev, T. Wysokinski, D. Chapman, D. Tonchev, S. Kasap, Samarium-doped oxyfluoride glass-ceramic as a new fast erasable dosimetric detector material for microbeam radiation cancer therapy applications at the Canadian synchrotron. J. American Ceramic Society. 97, 1976-80 (2014)

${ }^{29}$ B. Morrell, G. Okada, S. Vahedi, C. Koughia, A. Edgar, C. Varoy, G. Belev, T. Wysokinski, D. Chapman, R. Sammynaiken, S. Kasap, Optically erasable samarium-doped fluorophosphate glasses for high-dose measurement in microbeam radiation therapy. J. Appl. Phys. 115, 063107 (2014)

${ }^{30}$ G. Belev, G. Okada, D. Tonchev, C. Koughia, C. Varoy, A. Egar, T. Wysokinski, D. Chapman, S. Kasap, Valency conversion of samarium ions under high dose synchrotron generated x-ray radiation. Phys. Status Solidi C. 8, 2822-25 (2011) 
${ }^{31}$ A. Edgar, C. Varoy, C. Koughia, G. Okada, G. Belev, S. Kasap, High-resolution x-ray imaging with samarium-doped fluoroaluminate and fluorophosphate glass. Journal of Non-Crystalline Solids. 377, 124-128 (2013)

32 S. Vahedi, G. Okada, B. Morrell, E. Muzar, C. Koughia, A. Edgar, C. Varoy, G. Belev, T. Wysokinski, D. Chapman, S. Kasap, X-ray induced $\mathrm{Sm}^{3+}$ to $\mathrm{Sm}^{2+}$ conversion in fluorophosphate and fluoroaluminate glasses for the monitoring of high-doses in microbeam radiation therapy. Journal of Applied Physics. 112, 073108 (2012)

${ }^{33}$ G. Okada, B. Morrell, C. Koughia, A. Edgar, C. Varoy, G. Belev, T. Wysokinski, D. Chapman, S. Kasap, Spatially resolved measurement of high doses in microbeam radiation therapy using samarium doped fluorophosphate glasses. Applied Physics Letters. 99, 121105 (2011)

${ }^{34}$ G. Okada, S. Vahedi, B. Morrell, C. Koughia, G. Belev, T. Wysokinski, D. Chapman, C. Varoy, A. Edgar, S. Kasap, Examination of the dynamic range of Sm-doped glasses for highdose and high-resolution dosimetric applications in microbeam radiation therapy at the Canadian synchrotron. Optical Materials. 35, 1976-80 (2013)

${ }^{35}$ F. Chicilo, C. Koughia, R. Curry, R. Gwilliam, R. Ahumada-Lazo, A. Edgar, D. Binks, D. Chapman, S. Kasap, X-ray induced Sm-ion valence conversion in Sm-ion implanted fluoroaluminate glasses towards high-dose radiation measurement. J Mater Sci: Mater Electron. 1-7 (2019)

${ }^{36}$ J. Izewska, G. Rajan, Chapter 3: Radiation dosimeters. Podgorsak EB, editor. Radiation oncology physics: a handbook for teachers and students. (2015)

${ }^{37}$ N. Kitamura, J. Hayakawa and H. Yamashita, Optical properties of fluoroaluminate glasses in the UV region J. Non-Crst. Solids, 126, 155-160 (1990)

${ }^{38}$ D. Ehrt, T.Kittel, M. Will, S. Nolte, A. Tünnermann, Femtosecond-laser-writing in various glasses. J. Non-cryst. Solids. 345-346, 332-7 (2004)

${ }^{39}$ J. Livingstone, A. W. Stevenson, D. Häusermann, J.-F. Adam, Experimental optimisation of the X-ray energy in microbeam radiation therapy, Physica Medica, 45, 156 - 161 (2018)

${ }^{40} \mathrm{https}$ ://www.oem-xray-components.siemens.com/x-ray-spectra-simulation (accessed on 20 March 2019)

${ }^{41}$ A. Lipson, S. G. Lipson, H. Lipson, Chapter 12: Image formation. Cambridge University Press. Optical Physics. (2018)

${ }^{42}$ F. Salvat, M. Fernández-Varea, and J. Sempau, PENELOPE, a code system for Monte Carlo simulation of electron and photon transport. NEA Data Bank, Workshop Proceeding. 4-7 (2003)

${ }^{43}$ A.L. Hanson, F.H. Geisler, Microbeam Advancement, Inc. and Copernicus Dynamics, Inc., To be published

44 T. Goorley, M. James, T. Booth, F. Brown, J. Bull, L. Cox, Initial MCNP6 Release Overview MCNP6 version 1.0. Nuclear Technology. 180, 298-315 (2012) DOI: 10.13182/NT11-135

45 J. Qiu, K. Miura, T. Suzuki, T. Mitsuyu, Permanent photoreduction of $\mathrm{Sm}^{3+}$ to $\mathrm{Sm}^{2+}$ inside a sodium aluminoborate glass by an infrared femtosecond pulsed laser. Appl. Phys. Lett. 74, 10-12 (1999) https://doi.org/10.1063/1.123117 
${ }^{46}$ T.V. Bocharova, G.O. Karapetyan, A.M. Mironov, N.M. Mishchenkov, N.O. Tagil'steva, Irradiation-induced and postirradiation processes in fluoroaluminate glasses. Inorg Mater. 42 671-80 (2006) https://doi.org/10.1134/S0020168506060173

${ }^{47}$ D. Griscom, Defect Centers in heavy-metal fluoride glasses: a review. J. Non-Cryst. Solids. 161, 45-51 (1993) https://doi.org/10.1016/0022-3093(93)90667-M

${ }^{48}$ L. Ruihua, W.Haobing, G. Fuxi, ESR study of temperature dependence of colour centers in $\gamma$ ray irradiated fluoride glasses J. Non-Cryst. Solids. 140, 194-8 (1992) https://doi.org/10.1016/S0022-3093(05)80766-5

${ }^{49}$ J.M. Boone, X-ray production, interaction, and detection in diagnostic imaging Handbook of Medical Imaging vol 1 ed J Beutel, H L Kundel and R L Van Metter(Bellingham: SPIE Press, 2000) Chapter 1, pp 1-78, Equation 1.22b.

${ }^{50}$ B. Górka, B. Nilssona, R. Svensson, A. Brahme, P. Ascarelli, D.M. Trucchi, G. Conte, R. Kalish, Design and characterization of a tissue-equivalent CVD-diamond detector for clinical dosimetry in high-energy photon beams2000 X-ray production, interaction, and detection in diagnostic imaging Handbook of Medical Imaging, Physica Medica, 24 (2008), 159-168 